\title{
La Constitución mexicana y el derecho internacional de los derechos humanos*
}

\section{The Mexican Constitution and the International Human Rights Law}

\section{Jorge Carpizo**}

\begin{abstract}
SUMARIO: I. Los antecedentes, los primeros pasos y la consolidación del derecho internacional de los derechos humanos. II. El sistema interamericano de protección de los derechos humanos. III. La Constitución mexicana y los tratados internacionales: su jerarquía normativa y la jurisprudencia. IV. La Comisión Interamericana de Derechos Humanos. V. La Corte Interamericana de Derechos Humanos y el control difuso de convencionalidad. VI. México y la Corte Interamericana de Derechos Humanos. VII. Los Comités de Naciones Unidas para la protección de los derechos humanos y la Corte Penal Internacional.
\end{abstract}

* Artículo recibido el 8 de agosto de 2011 y aprobado para publicación el 28 de septiembre de 2011.

** Investigador emérito de la UNAM, de la cual fue Rector, adscrito al Instituto de Investigaciones Jurídicas, donde se desempeñó como director; investigador nacional emérito del Sistema Nacional de Investigadores; presidente del Instituto Iberoamericano de Derecho Constitucional.

Agradezco a mis colegas los doctores Jorge Ulises Carmona Tinoco y Eduardo Ferrer Mac-Gregor P. sus atinadas observaciones y el tiempo que le dedicaron a leer el manuscrito. Cualquier error que el ensayo pueda contener es responsabilidad exclusiva del autor. Asimismo agradezco el apoyo del becario Jesús Eulises González y de la sra. Isabel Cacho, quien transcribió los manuscritos. 
RESUMEN: El presente trabajo tiene por objeto mostrar al lector la interacción que existe entre la Constitución Política de los Estados Unidos Mexicanos y el derecho internacional de los derechos humanos. El autor inicia explicando los orígenes de esta área del derecho internacional así como los principios básicos de su operación. Continúa a exponer el funcionamiento del sistema regional de derechos humanos, explicando en detalle los dos pilares del sistema: la Comisión y la Corte Interamericanas de Derechos Humanos. Realiza un análisis de las disposiciones constitucionales mexicanas, Adentrándose en los diversos criterios jurisprudenciales emitidos por la Suprema Corte de Justicia de la Nación, relativas a la jerarquía de una de las más importantes fuentes de derecho internacional dentro del sistema mexicano: los tratados internacionales. Por último, presenta a detalle el papel de México ante la Corte Interamericana de Derechos Humanos, así como la relación que guarda este país con la Corte Penal Internacional y los diferentes comités de protección de derechos humanos pertenecientes a la Organización de Naciones Unidas.

Palabras clave: jerarquía normativa, recepción nacional del derecho internacional de los derechos humanos, sistema interamericano de derechos humanos, Convención Americana de Derechos Humanos, protección de derechos humanos en México.

ABSTRACT: This paper aims to show the reader the interaction between the Constitution of the United Mexican States and the International Law of human rights. The author begins by explaining the origins of this area of international law and the basic principles of its operation. Continues to expose the functioning of the regional human rights system, explaining in detail the two pillars of the system: the Inter-American Commission and the Inter-American Court of Human Rights. An analysis of Mexican constitutional provisions, entering the various jurisprudential criteria issued by the Supreme Court of Justice of the Nation regarding the hierarchy of one of the most important sources of International Law within the Mexican legal system: international treaties. Finally, the author presents in detail the role of Mexico in the InterAmerican Court of Human Rights, and the relationship that this country keeps with the International Criminal Court and the various United Nations committees for the protection of human rights.

Descriptors: Legal hierarchy; Domestic reception of International Law of human rights; Inter-american human rights system; American Convention on Human Rights, Protection of human rights in Mexico.

Résumé: Cet article vise à montrer au lecteur l'interaction entre la Constitution des Etats-Unis du Mexique et du droit international des droits humains. L'auteur commence par expliquer les origines de ce domaine du droit international et des principes fondamentaux de son fonctionnement. Continuer à exposer le fonctionnement du système régional des droits humains, expliquant en détail les deux piliers du système: la Commission et la Cour interaméricaine des droits de l'homme. Il fait une analyse des dispositions constitutionnelles du Mexique, en entrant aux différents critères jurisprudentiels délivré par la Cour Suprême du Mexique, concernant la hiérarchie de l'une des plus importantes sources de droit international dans le système mexicain: les traités internationaux. Finalement, On analyse en détail le rôle du Mexique à la Cour Interaméricaine des droits de l'homme, et la relation qui maintient ce pays avec la Cour Pénale Internationale et les divers comités pour la protection des droits de l'homme appartenant à l'Organisation des Nations Unies.

Mots-clés: Hiérarchie des règles, réception nationale du droit international des droits de l'homme, système Interaméricain de droits de l'homme; Convention américaine relative aux droits de l'homme, la protection des droits de l'homme au Mexique. 


\section{LOS ANTECEDENTES, LOS PRIMEROS PASOS Y LA CONSOLIDACIÓN DEL DERECHO INTERNACIONAL DE LOS DERECHOS HUMANOS}

1. El derecho internacional de los derechos humanos abarca los sistemas universal y regionales instituidos por los Estados, en ejercicio de su soberanía, por medio de convenciones, tratados y pactos multilaterales, que los obligan, con la finalidad de proteger los derechos humanos de las personas bajo su jurisdicción, tanto a través del reconocimiento de dichos derechos como de la creación de garantías procesales para los casos en que el orden interno no ha sido efectivo para defenderlos.

Además, los órganos que aplican el derecho internacional de los derechos humanos se pueden auxiliar de las disposiciones derivadas de las fuentes del derecho internacional, en particular, las provenientes de la costumbre, de los principios generales del derecho y del jus cogens ${ }^{1}$ en la aplicación e interpretación de dichos tratados, convenciones y pactos.

2. Tres distinguidos juristas, especialistas del derecho internacional de los derechos humanos, consideran que las singularidades de éste son:

a) Su índole ideológica, en cuanto su fundamento se encuentra en la noción de la superioridad de los valores inherentes a la dignidad de la persona humana, misma que debe ser respetada por todos los Estados, y que "aspira a expresar una ideología común de la humanidad”.

1 El jus cogens, de acuerdo con la Convención de Viena sobre el Derecho de los Tratados, se integra por las normas aceptadas y reconocidas por la comunidad internacional de los Estados en su conjunto, que no admiten acuerdo en contrario y únicamente pueden ser modificadas por una norma ulterior del derecho internacional general que posea ese mismo carácter.

${ }^{\text {La }}$ norma del jus cogens es de cumplimiento obligado, lo cual la diferencia de la costumbre internacional; compromete a todos los Estados, al establecer obligaciones erga omnes y, generalmente, se acepta que es parte del derecho internacional general, no del regional.

Ejemplos de normas de jus cogens son: la privación arbitraria de la vida, la prohibición de la tortura, la prohibición de crímenes contra la humanidad, el acceso a la justicia; en caso de conflictos armados, la prohibición de ataques contra civiles, el trato de civiles y militares conforme a principios de humanidad, entre otros, y el principio base de pacta sunt servanda (los tratados deben ser respetados porque obligan). 
b) Es complementario del derecho interno, debido a que sólo se actualiza cuando los instrumentos nacionales protectores fracasan, no existen o no funcionan en la realidad. Además, la Corte Interamericana de Derechos Humanos precisa que tiene carácter subsidiario y coadyuvante.

c) Es una garantía mínima, en virtud de que no aspira a ser omniprotector, sino que son los derechos mínimos que toda persona debe poseer. Si el derecho interno u otro tratado reconoce una garantía más amplia, ésta es la que debe ser aplicada. Es decir, debe prevalecer el precepto y garantía más favorable a la persona humana.

En esa forma, quien aplica el derecho, generalmente es el juez, tanto el nacional como el supra o internacional, sin tomar en cuenta la fuente de la norma - convencional, constitucional o secundaria-, debe aplicarla o interpretarla en el sentido que más favorezca a la persona lesionada. Este principio lo recogen varios y diversos tratados, convenciones y pactos que México ha ratificado, así como nuestra Suprema Corte, ${ }^{2}$ y la Constitución mexicana a partir de la reforma de junio de 2011 al artículo 1o., al señalar: "Las normas relativas a los derechos humanos se interpretarán de conformidad con esta Constitución y con los tratados internacionales de la materia favoreciendo en todo tiempo a las personas la protección más amplia”.

A dicho principio se le conoce como pro homine o "a favor de la persona”.

2 Sagües, Néstor P., "La interpretación de los derechos humanos en las jurisdicciones nacional e internacional”, en Palomino Manchego, José E., y Remoti Carbonell, José Carlos (coords.), Derechos humanos y Constitución en Iberoamérica (Libro Homenaje a Germán J. Bidart Campos), Lima, Instituto Iberoamericano de Derecho Constitucional-Grijley, 2002, pp. 36-38; Corcuera Cabezut, Santiago, "La incorporación y aplicación de los tratados internacionales sobre derechos humanos en el sistema jurídico mexicano”, en Martín, Claudia et al. (comps.), Derecho internacional de los derechos humanos, México, Universidad Iberoamericana y Fontamara, 2006, pp. 166-170; Silva Meza, Juan N. y Silva García, Fernando, Derechos fundamentales, México, Porrúa, 2009, pp. 31-35; Carpizo, Enrique, Derechos fundamentales. Interpretación constitucional y la Corte y los derechos, México, Porrúa-Instituto Mexicano de Derecho Procesal Constitucional, 2009, p. 96; Cuarto Tribunal Colegiado en Materia Administrativa del Primer Circuito, amparo directo 202/2004, del 20 de octubre, 2004, tesis I. $4^{\circ}, \mathrm{A}, 464 \mathrm{~A}$. 
d) Es derecho protector, vigilante de que se cumplan los tratados y convenciones internacionales de derechos humanos en beneficio de los habitantes de los Estados parte. Por tanto, en dichos tratados se justifican criterios teleológicos de interpretación; es el principio de interpretatio pro homine.

e) La progresividad que se fortalece por la gran flexibilidad de los preceptos de los tratados y convenciones de la materia, y que permiten que los Estados partes extiendan la protección contenida en esos instrumentos internacionales y, a su vez, trae implícita la proscripción de medidas regresivas, ${ }^{3}$ y la Constitución mexicana incorporó esta característica en el artículo 1o. a partir de junio de 2011.

3. El derecho internacional de los derechos humanos es relativamente reciente. Es sobre todo la reacción de la humanidad — de los países vencedores y sus aliados - a las atrocidades cometidas durante la Segunda Guerra Mundial, de las cuales tampoco ellos dejaron de ser actores. El remordimiento es un sentimiento válido si impulsa acciones positivas.

Desde luego que tiene antecedentes en algunos tratados del siglo XIX, como los que persiguieron la abolición del tráfico de esclavos y la protección de las minorías cristianas en el entonces imperio otomano, y que fue la base del sistema de minorías que adoptó la Sociedad de las Naciones.

Esa Sociedad, fruto de la Primera Guerra Mundial, no incluyó preceptos sobre derechos humanos. No obstante, indirectamente sí protegió varios de ellos: a) se estableció un sistema internacional para la protección de minorías, como consecuencia de la creación de nuevos países y la alteración de las fronteras en Europa; $b$ ) el sistema de mandatos, en el cual las colonias de los Estados que habían perdido la guerra, pasaron a ser administradas por los países vencedores, mismos que estaban obligados a velar por el desarrollo y el bienestar de las poblaciones nativas de esas ex colonias; c) se creó la Organización Internacional del Trabajo para promover y vigilar el cumplimiento de las obligaciones internacio-

3 Buergenthal, Thomas et al., Manual internacional de derechos humanos, Caracas-San José, Instituto Interamericano de Derechos Humanos y Editorial Jurídica Venezolana, 1990, pp. 173-175. 
nales del trabajo, y d) algunas protecciones a los extranjeros, y aunque ellos no podían acudir a instancias internacionales, sí el Estado del cual eran nacionales. ${ }^{4}$

4. En 1941, durante la Segunda Guerra Mundial, el presidente estadounidense Franklin D. Roosevelt pronunció un importante discurso sobre cuatro libertades fundamentales y esenciales que debían fundamentar un orden moral: la de expresión, la de creer en una religión, el abrigo contra la miseria y la liberación del miedo. Durante la guerra los aliados comenzaron a pensar en ellas, y al respecto se celebraron reuniones y conferencias. Es probable que de esos años sobresalga el proyecto de Dumbarton Oaks, que prepararon las delegaciones oficiales de Estados Unidos, Gran Bretaña y Rusia en relación con la organización que sustituiría a la Sociedad de Naciones.

Dichos discursos y proyecto son, entre otros, los antecedentes de la creación de la Organización de Naciones Unidas (ONU), cuya Carta marca el comienzo del derecho internacional de los derechos humanos, aunque no con la contundencia que se hubiera esperado de las potencias vencedoras de la Segunda Guerra Mundial, en virtud de que éstas tenían problemas graves de violación de derechos humanos al interior de sus respectivos países. No obstante, la Carta fue la semilla que permitió que el árbol protector comenzara a crecer, aunque al principio con lentitud.

Los artículos 55 y 56 de esa Carta fueron muy significativos, porque ligaron la paz y las relaciones amistosas entre las naciones al respeto universal a los derechos humanos y a las libertades fundamentales, así como a niveles de vida más elevados con derecho al trabajo permanente para todos y a condiciones de progreso y desarrollo económico y social. Los Estados se comprometieron a tomar medidas para la realización de dichos propósitos, ya fuera en forma conjunta o separada, con la cooperación de la Organización ${ }^{5}$. Por otra parte, los instrumentos con que se dotó a la ONU para alcanzar esos objetivos fueron casi inexistentes.

4 Ibidem, pp. 9-14; Sepúlveda, César, Estudios sobre derecho internacional y derechos humanos, México, CNDH, 2000, p. 14; Cassin, René, “El problema de la realización efectiva de los derechos humanos en la sociedad universal”, en Herrendorf, Daniel L., (comp.), Teoría general y política de los derechos humanos, México, Comisión Nacional de los Derechos Humanos, 1992, pp. 176-179.

5 Carta de la ONU. Artículo 55: "Con el propósito de crear las condiciones de estabilidad y bienestar necesarias para las relaciones pacíficas y amistosas entre las naciones, basadas en el 
No obstante, la Carta dio un vuelco a la concepción tradicional del derecho internacional, de que éste regía exclusivamente las relaciones entre los Estados, para abrir las puertas a los individuos y a los grupos sociales como sujetos de dicho derecho. Así comenzaba una nueva etapa, los pinitos del derecho internacional de los derechos humanos.

5. La Declaración Americana de los Derechos y Deberes del Hombre, de mayo de 1948, nació, en el seno de la IX Conferencia Interamericana celebrada en Bogotá, con la calidad de recomendación, y sin seguirse los procedimientos propios de un tratado o convención.

Hoy en día esa Declaración tiene valor jurídico por las siguientes razones: a) constituye una fuente de obligaciones internacionales para los Estados miembros de la OEA; $b$ ) en 1959 se creó la Comisión Interamericana de Derechos Humanos (CIDH) con la finalidad de que promueva el respeto y la defensa de los derechos incluidos en dicha Declaración; c) en 1960, el Estatuto de la CIDH precisó que los derechos humanos que se protegían eran los contenidos en la Declaración; d) la $\mathrm{CIDH}$ ha tenido una actuación relevante, sus recomendaciones y resoluciones son publicadas, conocidas y ponderadas por la Asamblea General de la OEA $; e$ ) es ya parte del derecho convencional, debido a que el Estatuto de la Comisión fue incorporado a la Carta de la OEA, al formar parte de la Declaración desde 1965, y especialmente en el Protocolo de Buenos Aires de 1967;f) en 1965 se atribuyó a la CIDH la facultad de conocer, tramitar y decidir quejas por violaciones de derechos humanos y éstos eran los contenidos en dicha Declaración; g) su aplicación ha propiciado una práctica que satisface los requisitos de la costumbre internacional,

respeto al principio de la igualdad de derechos y al de la libre determinación de los pueblos, la Organización promoverá:

a) niveles de vida más elevados, trabajo permanente para todos, y condiciones de progreso y desarrollo económico y social;

b) la solución de problemas internacionales de carácter económico, social y sanitario, y de otros problemas conexos; y la cooperación internacional en el orden cultural y educativo; y

c) el respeto universal a los derechos humanos y a las libertades fundamentales de todos, sin hacer distinción por motivos de raza, sexo, idioma o religión, y la efectividad de tales derechos y libertades".

Artículo 56:

"Todos los miembros se comprometen a tomar medidas, conjunta o separadamente, en cooperación con la Organización, para la realización de los propósitos consignados en el artículo 55”. 
porque las violaciones a las normas de la Declaración "son tratadas como infracciones a una regla de derecho internacional” y la actuación de la $\mathrm{CIDH}$ ha sido aprobada por los Estados del continente americano; $h$ ) en 1962, la Reunión de Punta del Este fortaleció y amplió las facultades de la Comisión, quedó clara la aceptación y el respaldo de los Estados partes a ésta; i) el Pacto de San José reforzó las funciones de la CIDH, ya que continuaría sus labores de protección de los derechos humanos, incluidos los de la Carta de la OEA y los de la Declaración Americana, aun respecto a los países que no suscribieron el Pacto de San José ni reconocieron la competencia contenciosa de la Corte Interamericana de Derechos Humanos (Corte IDH), además de sus funciones como órgano de ese $\mathrm{Pacto}^{6} ; j$ ) la propia $\mathrm{CIDH}$ ha reconocido la obligatoriedad de la Declaración Americana en el caso 2141, Informe 23/81, y k) lo mismo se encuentra en la jurisprudencia de la Corte IDH.

Es probable que la Declaración Americana de los Derechos y Deberes del Hombre habrá de denominarse Declaración Americana de Derechos y Deberes de la Persona, por resolución de la Asamblea General de la OEA que solicitó al Consejo Permanente el estudio de esta cuestión en 1998.

6. La Declaración Universal de Derechos Humanos de diciembre de 1948, asimismo, en la actualidad, tiene valor jurídico, el que fue reconocido, sin oposición de ningún Estado, en el acta final de la Conferencia Internacional sobre Derechos Humanos de Teherán de 1968, en la cual, con claridad, se asentó que "la Declaración enuncia una concepción común a todos los pueblos de los derechos iguales e inalienables de todos los miembros de la familia humana y la declara obligatoria para la comunidad internacional".

Además, la Declaración Universal ha sido el fundamento para que la Asamblea General de la ONU emita resoluciones que condenan violaciones de derechos humanos, ${ }^{7}$ y hoy es parte del derecho internacional consuetudinario, que obliga a todos los Estados.

6 Nikken, Pedro, En defensa de la persona humana, Caracas, Editorial Jurídica Venezolana, 1988, pp. 133-150.

7 Ortiz Ahlf, Loretta, "Fuentes del derecho internacional de los derechos humanos", en Martín, Claudia, op. cit., pp. 27 y 43; Carbonell, Miguel, Neoconstitucionalismo y derechos fundamentales, Quito, Ecuador, Cevallos, 2010, pp. 50, 309 y 310; Cassin, René, op. cit., pp. 183-187. 
Un gran mérito de la Declaración Universal fue que logró el consenso de los Estados miembros de la ONU. Ningún Estado votó en contra, aunque hubo ocho abstenciones. Urgía su aprobación, porque ya había comenzado la Guerra Fría; se abría una interrogación sobre su viabilidad.

Un año después, en 1949, la Comisión de Derechos Humanos de la ONU comenzó el proceso para la redacción de un pacto que precisara los derechos y las libertades de la Declaración Universal, que la hiciera obligatoria, y que estableciera la organización y los procedimientos para la presentación de quejas por las violaciones del pacto. Comenzaba un trayecto prolongado y lleno de vicisitudes.

Antes de proseguir asiento un dato histórico: la declaración originalmente se iba a denominar Declaración Internacional de los Derechos del Hombre. La Asamblea General de la ONU, a propuesta de René Cassin, cambió la noción de Internacional por Universal para resaltar que el individuo, si bien es ciudadano de su país, lo es también del mundo y, como tal, sujeto directo del derecho internacional y merecedor de su protección.

Derechos del hombre tiene una connotación individualista muy importante, sin duda alguna, ligada a las declaraciones de finales del siglo XVIII. Derechos humanos posee un panorama más amplio: ampara, asimismo, los derechos sociales, económicos, culturales y de solidaridad, y lo que las nuevas necesidades irán precisando para su reconocimiento.

7. En 1951, la Comisión de Derechos Humanos de la ONU finalizó el proyecto de pacto, cuya redacción había comenzado dos años antes. La Asamblea General determinó que debían ser dos pactos para separar los de carácter individual de aquellos de índole social y económica. En 1954, esa Comisión había terminado la redacción de los dos proyectos de pactos; se discutieron durante diez años, y en diciembre de 1966 la Asamblea General los hizo suyos.

El Pacto Internacional de Derechos Económicos, Sociales y Culturales entró en vigor en enero de 1976, y el Pacto Internacional de Derechos Civiles y Políticos en marzo de ese mismo año.

Ambos establecen obligaciones convencionales para los Estados que los han ratificado. En consecuencia, su ámbito desborda la exclusiva jurisdicción interna de los Estados.

En los dos pactos y sus protocolos se reconocen derechos adicionales a los inscritos en la Declaración Universal (algunos derechos incluidos 
en ésta no se encuentran en los pactos), y establecen hasta el día de hoy, lo que próximamente se modificará, aunque de manera distinta, sistemas para garantizar que los Estados los cumplan. El Protocolo Facultativo del Pacto Internacional de Derechos Civiles y Políticos permite la presentación de peticiones individuales en relación con violaciones de derechos contemplados en el propio Instrumento, así como quejas interestatales.

En cambio, el artículo 2. 1 del Pacto Internacional de Derechos Económicos, Sociales y Culturales dispone:

Cada uno de los Estados Partes en el presente Pacto se compromete a adoptar medidas, tanto por separado como mediante la asistencia y la cooperación internacionales, especialmente económicas y técnicas, hasta el máximo de los recursos de que disponga, para lograr progresivamente, por todos los medios apropiados, inclusive en particular la adopción de medidas legislativas, la plena efectividad de los derechos aquí reconocidos.

El 10 de diciembre de 2008 se adoptó el Protocolo Facultativo del Pacto Internacional de los Derechos Económicos, Sociales y Culturales, que otorga al Comité de Derechos Económicos, Sociales y Culturales competencia para recibir y dar trámite a peticiones individuales respecto a hechos que impliquen alguna violación a derechos protegidos por el Pacto. El mencionado Protocolo aún no entra en vigor.

Con ambos pactos se dieron pasos adelante en la protección internacional de los derechos humanos. México los ratificó en 1981.

\section{EL SISTEMA INTERAMERICANO DE PROTECCIÓN}

DE LOS DERECHOS HUMANOS

8. Sin embargo, la defensa más acabada, y hasta ahora más efectiva, de los derechos humanos se encuentra en los sistemas regionales, especialmente el europeo y el americano, al existir órganos jurisdiccionales cuyas resoluciones son de cumplimiento obligatorio para los Estados que han reconocido la competencia contenciosa de alguno de esos órganos. 
El sistema americano se fortaleció y entró en una nueva etapa con la adopción de la Convención Americana sobre Derechos Humanos del 22 de noviembre de 1969, que inició su vigencia el 18 de julio de 1978, y a la que comúnmente se denomina Pacto de San José, por haberse suscrito en la capital de Costa Rica.

Dicho Pacto de San José se caracteriza por:

a) Una enumeración amplia de los derechos humanos protegidos.

b) El otorgamiento de nuevas facultades a la CIDH.

c) En consecuencia, la ratificación del valor jurídico de dicha Declaración.

d) La creación de la Corte Interamericana de Derechos Humanos (Corte IDH) con dos distintas competencias: una consultiva y otra contenciosa para vigilar el cumplimiento y hacer efectivos los derechos reconocidos en dicho Pacto. Hoy en día esa protección se extiende a otros instrumentos regionales, como la Convención Interamericana para Prevenir y Sancionar la Tortura, el Protocolo Adicional a la Convención Americana sobre Derechos Humanos en Materia de Derechos Económicos, Sociales y Culturales, la Convención Interamericana sobre Desaparición Forzada de Personas, y la Convención Interamericana para Prevenir, Sancionar y Erradicar la Violencia contra la Mujer. ${ }^{8}$

El Pacto de San José se inspiró en forma especial en el sistema regional europeo con la creación de una Corte de plena jurisdicción, aunque, desde luego, existen entre ellas marcadas diferencias.

México es parte de ese Pacto desde marzo de 1981. Sin embargo, se tardó en reconocer la competencia contenciosa de la Corte IDH; lo

8 Así lo ha establecido la propia Corte IDH en el Caso Ibsen Cárdenas e Ibsen Peña vs. Bolivia. Fondo, Reparaciones y Costas, sentencia del 1o. de septiembre de 2010, Serie C, núm. 217, párr. 199: su competencia comprende "la aplicación de la Convención Americana y de otros tratados que le otorguen competencia”, y, desde luego, la interpretación de esos tratados.

Las resoluciones de la Corte se pueden consultar en García Ramírez, Sergio (coord.), La jurisprudencia de la Corte Interamericana de Derechos Humanos, México, UNAM-Instituto de Investigaciones Jurídicas. Se han editado siete tomos, el primero fue en 2001, reeditado en 2006, y el séptimo en 2010. En la coordinación de la edición de los dos últimos tomos, ha participado María Carmelina Londoño Lázaro. Los tomos contienen índices temáticos que son de especial utilidad. 
realizó hasta diciembre de 1998. Las dudas de algunos sectores eran muchas, en virtud de una anticuada noción de soberanía, ${ }^{9}$ ya que a partir del mencionado reconocimiento, en 1998, el Estado mexicano está obligado a acatar las sentencias de la Corte IDH, órgano que tiene facultades para declarar qué acciones de autoridades mexicanas son contrarias a disposiciones de la Convención Americana o a algunos otros tratados del sistema interamericano, sin importar su naturaleza: actos administrativos, leyes, sentencias e incluso normas constitucionales.

En esta forma, tratándose del Pacto de San José y de la protección de los derechos humanos que reconoce, incluso la SCJN no es la intérprete última de ese Pacto, sino la Corte IDH, cuya jurisprudencia obliga a todas las autoridades.

México, al reconocer la competencia jurisdiccional o contenciosa de la Corte IDH, declaró que lo hacía en ejercicio de su soberanía, no en su menoscabo, y que tal decisión se fundamentaba en la tradición constitucional de nuestro país de preservar y proteger los derechos y las libertades del hombre, no exclusivamente mediante proclamas y declaraciones, sino, y en forma fundamental, también a través de garantías.

La Secretaría de Relaciones Exteriores de ese entonces manifestó: "La aceptación de la competencia [contenciosa] de la Corte Interamericana constituye un hito en el tránsito de mi país hacia una sociedad cada vez más democrática, abierta y respetuosa de los derechos inalienables de todos sus integrantes” y, en diversa ocasión, expresó:

Me congratulo de que a los mecanismos de derechos humanos en los que México participa ya en forma constructiva, respetuosa y transparente, se sume hoy la

9 En 1981, el Poder Ejecutivo Federal, para no aceptar la plena jurisdicción de la Corte IDH, asentó lo siguiente: "Por otra parte, no procedería que el gobierno mexicano hiciese, al menos por ahora, la declaración prevista en el artículo 62 de la Convención, reconociendo como obligatoria de pleno derecho y sin convención especial, la competencia de la Corte Interamericana de Derechos Humanos, que se prevé en el Capítulo VIII, sobre todos los casos relativos a la interpretación o aplicación de esta Convención... La aceptación de la jurisdicción obligatoria y automática de la Corte Interamericana estaría fuera de lugar por ahora, toda vez que la legislación nacional prevé los recursos necesarios para corregir cualquier falla en la estructura de preservación de las garantías individuales y sociales en el país”. Véase Archivo Histórico Diplomático Mexicano: Convenciones sobre Derechos Humanos, México, SRE, 1981, pp. 22 y 23, párrafo que constituye un testimonio fiel de la concepción jurídica nacionalista que imperaba en aquel entonces. 
Corte Interamericana de Derechos Humanos. Manifiesto nuestra voluntad para cooperar con ella dentro del marco legal establecido y reitero nuestra disposición para avanzar conjuntamente en la promoción y defensa de los derechos inalienables de todo ser humano. ${ }^{10}$

\section{LA CONSTITUCIÓN MEXICANA Y LOS TRATADOS INTERNACIONALES:}

\section{SU JERARQUÍA NORMATIVA Y LA JURISPRUDENCIA}

9. Antes de presentar una síntesis de los aspectos más significativos de la CIDH y de la Corte IDH, me refiero al valor de los tratados internacionales, y específicamente a los de derechos humanos en el orden interno de los países. Cada Estado, en ejercicio de su soberanía, decide la jerarquía de los mismos.

Soberanía y derecho internacional de los derechos humanos no son conceptos antagónicos, sino deben ser armonizados en razón del valor de la persona humana y de su dignidad. El orden jurídico y político se crea para asegurar los derechos de la persona humana y, precisamente, por ello es que el Estado, en ejercicio de su soberanía, acepta las declaraciones, tratados, convenciones y pactos internacionales de derechos humanos, así como los mecanismos que van a vigilar y hacer efectivos dichos instrumentos internacionales, y los derechos que protegen.

Por ejemplo, el artículo 5o., inciso 2, de la Constitución de Chile, reformada en 1989, dispone:

El ejercicio de la soberanía reconoce como limitación el respeto a los derechos esenciales que emanan de la naturaleza humana. Es deber de los órganos del Estado respetar y proveer tales derechos, garantizados por la Constitución, así como por los tratados internacionales ratificados por Chile y que se encuentran vigentes.

10 La diferencia de conceptos y el tono empleados en 1998 contrasta grandemente con los de 1981, a lo que me refiero en la nota anterior. En menos de veinte años México no pudo evadir la corriente abrasadora y protectora del derecho internacional de los derechos humanos; véase García Ramírez, Sergio, "Admisión de la competencia contenciosa de la Corte Interamericana de Derechos Humanos”, en García Ramírez, Sergio y Castañeda Hernández, Mireya (coords.), Recepción nacional del derecho internacional de los derechos humanos y admisión de la competencia contenciosa de la Corte Interamericana, México, UNAM-Instituto de Investigaciones Jurídicas, SRE y Corte IDH, 2009, p. 30. 
10. Héctor Fix-Zamudio indica que la progresiva y constante influencia del derecho internacional, especialmente el de los derechos humanos, en las Constituciones de Iberoamérica se puede contemplar desde tres perspectivas: a) los tratados se encuentran inmediatamente debajo de la Constitución, pero con preeminencia sobre el derecho interno, como en Portugal, España, Guatemala, Costa Rica, El Salvador, Nicaragua y México; $b$ ) se reconoce que los tratados internacionales, en forma expresa o implícita, se encuentran al mismo nivel que la Constitución, como en Argentina, Brasil, Colombia y Venezuela, y c) la doctrina comienza a advertir una tendencia a que a esos tratados se les reconoce un carácter superior a la misma Constitución, como en el artículo 26 de la de Venezuela de 1999, la cual ordena que los instrumentos internacionales de derechos humanos prevalecen en el orden interno si establecen normas y garantías más favorables que aquellas contenidas en la Constitución y en las leyes. ${ }^{11}$

11. En México, la jerarquía de las normas la establece el artículo 133 c:

Esta Constitución, las leyes del Congreso de la Unión que emanen de ella y todos los Tratados que estén de acuerdo con la misma, celebrados y que se celebren por el Presidente de la República, con aprobación del Senado, serán la Ley Suprema de toda la Unión....

Desde 1969 sostuve que este artículo había que interpretarlo en conexión con otros preceptos constitucionales, como el 16, 40, 41, 103, 105 y 124, que señalan que la autoridad sólo puede actuar de acuerdo con la competencia que le señala la Constitución, que este principio constituye en México un derecho humano, y si se viola procede el juicio de amparo. En consecuencia, en nuestro país si existe una aparente contradicción entre la ley federal y la local, el problema no es de jerarquía entre ellas, sino de la competencia establecida en la Constitución, y hay que aplicar la ley que respeta la competencia constitucional y que, por tanto, la jerarquía de las normas en el orden jurídico mexicano, de acuerdo con el artículo 133 c. y los otros citados, es:

11 Fix-Zamudio, Héctor, "La creciente internacionalización de las Constituciones iberoamericanas, especialmente en la regulación y protección de los derechos humanos", Memoria 2008, México, El Colegio Nacional, 2009, pp. 88-90. 
- Constitución.

- Ley constitucional y tratado internacional.

- Ley federal y local.

En consecuencia, el tratado internacional se encuentra debajo de la Constitución, pero encima de las leyes federales y locales, y al mismo nivel de la ley constitucional, que es aquella que desarrolla o precisa la norma constitucional, como las leyes orgánicas de los poderes públicos y las reglamentarias de los preceptos constitucionales. ${ }^{12}$ Esta interpretación la había esbozado Mario de la Cueva, ${ }^{13}$ y era contraria a la jurisprudencia de la SCJN, que en una interpretación netamente gramatical del artículo 133 c, y no de carácter hermenéutico, sostenía que los tratados internacionales se encontraban al mismo nivel de las leyes federales. ${ }^{14}$

En mayo de 1999, la SCJN modificó su jurisprudencia tradicional para establecer la tesis siguiente: "Tratados internacionales. Se ubican jerárquicamente por encima de las leyes federales y en un segundo plano respecto de la Constitución federal". ${ }^{15}$ La tesis es correcta y precisa la jerarquía de los tratados internacionales en el orden jurídico mexicano: sólo por abajo de la Constitución, al mismo nivel de la ley constitucional y por encima de las leyes federales y locales. Sin embargo, en 2007 la SCJN, en una tesis aislada, vuelve a dudar de su interpretación de 1999, al señalar la existencia de "leyes generales" que prevalecen sobre los tratados internacionales. ${ }^{16}$

12 Carpizo, Jorge, "La interpretación del artículo 133 constitucional” en Boletín Mexicano de Derecho Comparado, México, UNAM, Instituto de Investigaciones Jurídicas, 1969, t. II, nueva serie, núm. 4, 3-32 pp., incorporado al libro Estudios constitucionales, México, Porrúa-UNAM, Instituto de Investigaciones Jurídicas, 2003, pp. 16-22.

13 Cueva, Mario de la, Teoría de la Constitución, México, Porrúa, 2008, pp. 113-115.

${ }_{14}$ Semanario Judicial de la Federación, P.C/92, tesis 205,596, Pleno, México, 1992, t. LX, p. 27.

15 Semanario Judicial de la Federación, P.LXXVII/99, tesis 192,867, Pleno, México, 1999, t. X, p. 46.

16 Carpizo, Jorge, "Los tratados internacionales tienen una jerarquía superior a las leyes federales. Comentario a la tesis 192,867 de la Suprema Corte de Justicia de la Nación”, en Cuestiones Constitucionales. Revista Mexicana de Derecho Constitucional, México, UNAM-Instituto de Investigaciones Jurídicas, 2007, núm. 3, 177-183 pp., incorporado al libro Temas constitucionales, México, Porrúa y UNAM-Instituto de Investigaciones Jurídicas, 2003, pp. 493-498. 
Todos los tratados internacionales, y desde luego los de derechos humanos, celebrados de acuerdo con el procedimiento previsto por el artículo 133 c son parte del derecho interno de México. Entonces, los derechos humanos protegidos en México son: a) los que la Constitución de 1917 y sus leyes federales y las Constituciones locales y sus leyes reconocen; $b$ ) más todos aquellos que no se encuentren en dichas normas, pero sí en los tratados internacionales ratificados por México, con lo cual se refuerza el reconocimiento y la defensa de los derechos humanos en nuestro país, y las características de progresividad, universalidad, indivisibilidad, irreversibilidad y eficacia directa; c) las resoluciones de la SCJN; d) la jurisprudencia de la Corte IDH, y e) los derechos humanos implícitos.

12. De esta forma, el derecho internacional de los derechos humanos es una de las fuentes del derecho constitucional mexicano, ${ }^{17}$ en cuanto amplía los derechos humanos reconocidos en nuestro orden jurídico interno, y en cuanto la jurisprudencia de los órganos jurisdiccionales - la Corte IDH - nos es obligatoria, sin desconocer los informes y recomendaciones de otros órganos creados en tratados internacionales de derechos humanos que México ha ratificado.

\footnotetext{
${ }^{\text {La }}$ tesis aislada de 2007 se localiza en Semanario Judicial de la Federación y su Gaceta, tesis P. IX, 2007, Pleno, México 2007, tomo XXV, p. 6, que señala:

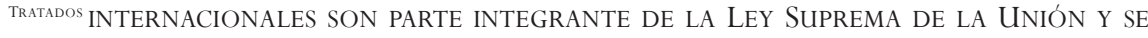
UBICAN JERÁRQUICAMENTE POR ENCIMA DE LAS LEYES GENERALES, FEDERALES Y LOCALES. INTERPRETACIÓN DEL ARTÍCULO 133 CONSTITUCIONAL. La interpretación sistemática del artículo 133 de la Constitución Política de los Estados Unidos Mexicanos permite identificar la existencia de un orden jurídico superior, de carácter nacional, integrado por la Constitución Federal, los tratados internacionales y las leyes generales. Asimismo, a partir de dicha interpretación, armonizada con los principios de derecho internacional dispersos en el texto constitucional, así como con las normas y premisas fundamentales de esa rama del derecho, se concluye que los tratados internacionales se ubican jerárquicamente abajo de la Constitución Federal y por encima de las leyes generales, federales y locales, en la medida en que el Estado Mexicano al suscribirlos, de conformidad con lo dispuesto en la Convención de Viena Sobre el Derecho de los Tratados entre los Estados y Organizaciones Internacionales o entre Organizaciones Internacionales y, además, atendiendo al principio fundamental de derecho internacional consuetudinario "pacta sunt servanda", contrae libremente obligaciones frente a la comunidad internacional que no pueden ser desconocidas invocando normas de derecho interno y cuyo incumpliendo supone, por lo demás, una responsabilidad de carácter internacional.
}

17 Carpizo, Jorge y Carbonell, Miguel, Derecho constitucional, México, Porrúa-UNAM, Instituto de Investigaciones Jurídicas, 2010, pp. 3-7. 
Los elementos enunciados en los incisos anteriores integran primordialmente un bloque constitucional de derechos humanos. Preciso, dicho bloque se integra por: a) nuestra Constitución y los preceptos secundarios que reconocen derechos humanos; $b$ ) las normas de derechos humanos contenidas en los tratados internacionales ratificados por nuestro país; c) el derecho internacional consuetudinario y el ius cogens; d) la jurisprudencia de la Corte IDH; e) las resoluciones sobre la materia de la SCJN, y f) los derechos humanos implícitos.

Todos esos componentes hay que respetarlos, interpretarlos y acatarlos, hay que contemplarlos como una unidad armónica que persiguen la misma finalidad: hacer vigente y real el principio de la dignidad humana a través de la mejor y más completa protección de los derechos humanos.

El bloque de constitucionalidad varía de país a país, pero tiene un tronco común: las convenciones multilaterales y la jurisprudencia de sus órganos. "Así, en algunas ocasiones, el bloque de convencionalidad al que me refiero con posterioridad] queda subsumido en el bloque de constitucionalidad, por lo que al realizar el control de constitucionalidad también se efectúa control de convencionalidad". Las interpretaciones de la Corte IDH a la normatividad convencional no se limitan a las sentencias en los casos contenciosos, sino que abarcan las demás resoluciones en las que se interpreta la Convención Americana, como las referentes a medidas provisionales, supervisión de cumplimiento de sentencias, solicitud de interpretación de la sentencia y las opiniones consultivas. ${ }^{18}$

Desde luego, no todas las piezas integrantes del bloque de constitucionalidad, en el aspecto del orden interno como en el externo, tienen la misma jerarquía. Por ejemplo, no es lo mismo una norma constitucional que una secundaria, una sentencia de un caso contencioso ante la Corte IDH que una opinión consultiva.

El bloque de constitucionalidad de los derechos humanos debe ser respetado por todos los titulares pasivos de los derechos humanos, desde el poder reformador de la Constitución, las autoridades y funcionarios administrativos, los legisladores, los jueces y los titulares de los

18 Ferrer Mac-Gregor, Eduardo, Voto razonado del juez ad hoc en relación con la sentencia de la Corte Interamericana de Derechos Humanos en el Caso Cabrera García y Montiel Flores vs. México del 26 de noviembre de 2010, San José, Costa Rica, 2010, pp. 11 y 18. 
órganos constitucionales autónomos de los tres niveles de gobierno, hasta los poderes fácticos e incluso los individuos. Así, una de las bases, y probablemente la principal, de este bloque de constitucionalidad son los principios ya mencionados de pro homine y de intepretatio pro homine, los cuales son extremadamente cercanos entre sí, y que hay que armonizarlos con los principios de jerarquía y de competencia, sin que exista una regla general de aplicación. ${ }^{19}$

La interpretación anterior se deriva de una correcta comprensión de los alcances del artículo 133 c. No obstante, el medio jurídico mexicano, con sus excepciones, era renuente a aceptar y reconocer lo que era y es obvio.

En dicha idea insistió la reforma constitucional de junio de 2011 al artículo 1o.:

En los Estados Unidos Mexicanos todas las personas gozarán de los derechos humanos reconocidos en esta Constitución y los tratados internacionales de los que el Estado Mexicano sea parte; así como de las garantías para su protección, cuyo ejercicio no podrá restringirse ni suspenderse, salvo en los casos y bajo las condiciones que esta Constitución establece. Las normas relativas a los derechos humanos se interpretarán de conformidad con esta Constitución y con los tratados internacionales de la materia, favoreciendo en todo tiempo a las personas la protección más amplia...

El artículo 1o. c, reformado en 2011, explicitó lo que la Constitución ya incorporaba. Desde luego que estoy de acuerdo con la nueva redacción. Lo único que me parece curioso es el cúmulo de manifestaciones del sector político y académico de que dicha reforma es muy importante y que la defensa de los derechos humanos va a tener un viraje positivo en el país.

Dicha reforma vino a decir lo que la Constitución ya decía y, como en otras ocasiones, su significado cabal es: ahora sí se va a aplicar la Consti-

19 Esta afirmación hay que apreciarla en sus contornos precisos. En el orden jurídico interno no es lo mismo la interpretación que realice un juez de Distrito o un Tribunal Superior de Justicia que un Tribunal Colegiado de Circuito o la SCJN. En el orden externo no es lo mismo una recomendación de la CIDH que una sentencia de la Corte IDH, y de este último órgano no es lo mismo una sentencia que una opinión consultiva, con todo el valor moral que posee, y que tal vez sea antesala de un criterio jurisprudencial o reglamentario. 
tución como siempre debió de haberse hecho. Esta es una peculiaridad del derecho constitucional mexicano, y por cierto no es para sentirse orgulloso de ella.

Habrá de verse si con ese "ahora si”, la protección de los derechos humanos va a mejorar en nuestro país.

13. En México, no hay que descuidar el conocimiento de los derechos humanos en las Constituciones de las entidades federativas, ya que algunas de ellas han sido o son más vanguardistas que la propia Constitución federal. La Constitución de Sinaloa, reformada en mayo de 2008 hace suyos en el artículo 4 bis, los derechos humanos previstos en los instrumentos internacionales e incorporados al orden jurídico mexicano. Se reconoce, entonces, la eficacia directa de esos instrumentos internacionales que vinculan a todos los poderes públicos de esa entidad federativa.

El mencionado artículo 4 bis establece siete reglas de interpretación en relación con los derechos humanos que incorporan las reglas más avanzadas en la materia. Así, por ejemplo, el inciso II precisa:

Su sentido se determinará de conformidad con los instrumentos internacionales incorporados al orden jurídico mexicano aplicables y atendiendo los criterios de los organismos internacionales de protección de los derechos humanos reconocidos por el Estado mexicano, especialmente de la Corte Interamericana de Derechos Humanos.

La Constitución de Tlaxcala, reformada en 2008, también acepta la eficacia y aplicación directa de los derechos humanos y, asimismo, establece en su artículo 16 cinco reglas para la interpretación de los derechos humanos; la segunda indica que

Su sentido se determinará de conformidad con los instrumentos internacionales incorporados al orden jurídico mexicano aplicables y atendiendo a los criterios de los organismos internacionales de protección de los derechos humanos reconocidos por el Estado mexicano. ${ }^{20}$

20 Véase Carmona Tinoco, Jorge Ulises, "La recepción de la jurisprudencia de la Corte Interamericana de Derechos Humanos en el ámbito interno. El caso de México”, en García 
14. México es parte de la Convención de Viena sobre el Derecho de los Tratados de 1969, en vigor desde el 27 de enero de 1980 y ratificada por nuestro país el 25 de septiembre de 1974. Esta Convención se apega al criterio contemporáneo más generalizado en cuanto al uso del término "tratado", como el más adecuado para abarcar todos los instrumentos en los cuales de cualquier modo se consigna un compromiso internacional y sobre los que existe una gran variedad de denominaciones, como convención, protocolo, pacto, carta, acuerdo o canje de notas.

Todo Estado queda obligado a respetar de buena fe, no sólo la letra, sino también el espíritu mismo del tratado internacional del cual es parte contratante. El incumplimiento o inejecución de cualquiera de las obligaciones insertas en el tratado es susceptible de ser sancionado por el derecho internacional a través del mecanismo de la responsabilidad internacional.

En términos generales, se puede decir que el derecho internacional, tanto el consuetudinario como el convencional, categóricamente no acepta que un Estado pueda invocar como causal de nulidad que su consentimiento, al obligarse a través de un tratado, viola una disposición de su derecho interno concerniente a la competencia para celebrar tratados.

No obstante, la Convención de Viena sobre el Derecho de los Tratados admitió una posición intermedia, al asentar que en caso de que la violación sea manifiesta - que resulte objetivamente evidente para cualquier Estado de buena fe- y afecte a una norma de importancia fundamental de su derecho interno, en esa hipótesis el Estado podrá alegar tal circunstancia como vicio de su consentimiento. ${ }^{21}$

La Corte IDH estableció jurisprudencia en el sentido de que un Estado no puede invocar el derecho interno para eludir una obligación internacional. ${ }^{22}$ Los artículos 26 y 27 de la Convención de Viena sobre

Ramírez, Sergio y Castañeda Hernández, Mireya (coords.), Recepción nacional del derecho internacional de los derechos humanos, cit., pp. 273-276.

21 Carpizo, Jorge y Gómez-Robledo, Alonso, "Los tratados internacionales, el derecho a la información y el respeto a la vida privada”, Boletín Mexicano de Derecho Comparado, México, UNAM, Instituto de Investigaciones Jurídicas, 2000, t. XXXIII, nueva serie, núm. 97, pp. 9-63, incorporado al libro Temas constitucionales, cit., pp. 435 y 436.

22 Corte IDH, Caso Hilaire. Excepciones preliminares, sentencia del 1o. de septiembre de 2011, Serie C, núm. 80, párr. 82. 
el Derecho de los Tratados de 1969, cuyos principios se incorporaron en la Convención Americana y recogen un principio básico del derecho internacional consuetudinario, en virtud del cual una parte no podrá invocar las disposiciones de su derecho interno como justificación del incumplimiento de un tratado. Los Estados deben cumplir sus obligaciones de buena fe. ${ }^{23}$

15. Los tratados de derechos humanos se caracterizan y se diferencian de los demás tratados por su técnica de interpretación teleológica; los tratados en general se llevan a cabo para beneficio de los Estados, al establecerse derechos y obligaciones mutuos; los de derechos humanos se aceptan en beneficio o en favor de las personas que se encuentren en su jurisdicción, ${ }^{24}$ aunque es imposible desconocer que muchos Estados se adhieren a una convención o tratado de derechos humanos no por gusto, sino por la presión de sus sociedades, expresada por organizaciones no gubernamentales, intelectuales, académicos, líderes sociales y artistas, o también como una muestra de prestigio para mostrar internacionalmente que en ese país existe un sistema democrático y protector de los derechos humanos, y que no teme la vigilancia internacional al respecto.

Pedro Nikken afirma correctamente que el derecho internacional de los derechos humanos nace más de la aspiración de los pueblos que de la voluntad de los gobiernos, los que ante las nuevas realidades históricas, posteriores a la Segunda Guerra Mundial, no podían eludir esa aguda aspiración colectiva. ${ }^{25}$ Sólo agrego que también era difícil para un gobierno, por los costos políticos que le acarrearía, no incorporarse a esa gran corriente internacional, aunque no la compartiera. Por ejemplo,

23 Convención de Viena sobre el Derecho de los Tratados de 1969:

Art. 26 "Pacta sunt servanda". Todo tratado en vigor obliga a las partes y debe ser cumplido por ellas de buena fe".

Art. 27 "El derecho interno y la observancia de los tratados. Una parte no podrá invocar las disposiciones de su derecho interno como justificación del incumplimiento de un tratado. Esta norma se entenderá sin perjuicio de lo dispuesto en el artículo 46".

u.N. Doc A/CONF. 39/27(1969), 1155 U.N.T.S. 331, que entró en vigor el 27 de enero de 1980 .

${ }^{24}$ Ortiz Ahlf, Loretta, op. cit., pp. 35 y 36; Corcuera Cabezut, Santiago, op. cit., pp. 162166.

25 Nikken, Pedro, En defensa de..., cit., p. 47. 
Sudáfrica no estaba decidida a abandonar el régimen del apartheid, pero no se atrevió a votar en contra de la Declaración Universal de Derechos Humanos, sólo se abstuvo. Los gobiernos no desean demostrar que no simpatizan con la causa de los derechos humanos por el costo político, reitero, que les representa en el ámbito internacional y con su propia población. Pareciera que para múltiples gobiernos adherirse a los tratados es sólo un instrumento de propaganda, una ocasión para manifestar su devoción por los derechos humanos, y que piensan que con posterioridad ya se verá qué acontece cuando se presenten los incumplimientos a las obligaciones contenidas en los tratados y a las sentencias emitidas por los órganos creados en los propios tratados.

A esta peculiaridad de los tratados de derechos humanos, la Corte IDH se ha referido con frecuencia, por ejemplo:

... los tratados modernos sobre derechos humanos, en general y, en particular, la Convención Americana no son tratados multilaterales de tipo tradicional, concluidos en función de un intercambio recíproco de derechos, para el beneficio mutuo de los Estados contratantes. Su objeto y fin son la protección de los derechos fundamentales de los seres humanos, independientemente de su nacionalidad, tanto frente a su propio Estado como frente a los otros Estados contratantes. Al aprobar estos tratados sobre derechos humanos, los Estados se someten a un orden legal dentro del cual ellos, por el bien común, asumen varias obligaciones no en relación con otros Estados, sino con los individuos bajo su jurisdicción... ${ }^{26}$

\section{Dicha Corte ha puntualizado que:}

El derecho internacional de los derechos humanos tiene por fin proporcionar al individuo medios de protección de los derechos humanos reconocidos internacio-

26 Corte IDH, Opinión Consultiva OC-2/82 del 24 de septiembre de 1982, Serie A, núm. 2, párr. 29: "El efecto de las reservas sobre la entrada en vigencia de la Convención Americana sobre Derechos Humanos”. Tesis que se reitera en Corte IDH, Caso de la Corte Constitucional (Aguirre Roca, Rey Ferry y Revoredo Marsano) vs. Perú, sentencia del 31 de enero de 2001, Serie C, núm. 71, párr. 89, al afirmar que la finalidad de la protección internacional de los derechos humanos consiste en la protección a las personas en contra del ejercicio arbitrario del poder del Estado, lo que reiteró en la sentencia que se cita en la siguiente nota. 
nalmente frente al Estado. En la jurisdicción internacional, las partes y la materia de la controversia son, por definición, distintas de la jurisdicción interna. ${ }^{27}$

16. A México le costó trabajo ratificar algunos de los tratados más importantes de derechos humanos, debido a la idea tradicional de soberanía que prevaleció durante muchos años en los medios político, jurídico y académico. Los dos Pactos de la ONU de 1966 los ratificó hasta 1981. La Convención Americana sobre Derechos Humanos de 1969 también hasta ese mismo año de 1981, y sin reconocer la competencia contenciosa de la Corte IDH. Asimismo, en 1981 se ratificaron otros importantes instrumentos internacionales sobre la materia. La renuencia a ratificar dichos tratados bien se ejemplifica con que se adhirió hasta el año 2000 a la Convención sobre el Estatuto de los Refugiados de 1951, lo cual fue absurdo, tratándose de un país que siempre tuvo las puertas abiertas a miles de refugiados, como aconteció en los casos de la guerra civil española o de las dictaduras de América Latina.

Después de las ratificaciones de 1981, la situación cambió en los últimos años de esa década, y a partir de entonces se ha fortalecido: México ya no es de los últimos países civilizados en adherirse a los instrumentos internacionales de derechos humanos.

En la actualidad, nuestro país es parte de casi todos los tratados o convenciones importantes sobre derechos humanos, ${ }^{28}$ y que son numerosos.

Los más importantes son los de carácter general, y de los cuales se desprenden aquellos sobre derechos humanos específicos. En orden cronológico se pueden recordar: la Declaración Americana sobre los Derechos y Deberes del Hombre, la Declaración Universal de los Derechos Humanos, los Pactos de las Naciones Unidas sobre Derechos

27 Corte IDH, Caso de los Hermanos Gómez Paquiyauri, sentencia del 8 de julio de 2004, Serie C, núm. 110, párr. 73.

28 Carpizo, Jorge, “México: Poder Ejecutivo y derechos humanos, 1975-2005”, Boletín Mexicano de Derecho Comparado, México, UNAM, Instituto de Investigaciones Jurídicas, 2009, t. XLII, nueva serie, núm. 126, pp. 1269-1279; véase Pedroza de la Llave, Susana y García Huante, Omar (comps.), Compilación de instrumentos internacionales de derechos humanos, firmados y ratificados por México, México, CNDH, 2003, t. I, 759 pp., y t. II, 706 pp. Asimismo, véanse www.ordenjuridico.gob.mx/derechos_humanos.php y www2.scjn.gob.mx/tratadosinternacionales/ default.htm. 
Civiles y Políticos, y sobre los Económicos, Sociales y Culturales, la Convención Americana sobre Derechos Humanos y el Protocolo Adicional a la Convención Americana sobre Derechos Humanos en materia de Derechos Económicos, Sociales y Culturales.

17. En la interpretación de los tratados de derechos humanos existe un "margen de apreciación nacional”, en el cual el tribunal del país está autorizado a tomar en cuenta las peculiaridades y realidades jurídicas, económicas y sociales de esa nación, sin que se viole el tratado, y siempre y cuando ese "margen" sea susceptible de control internacional, debido a que él no debe implicar un subterfugio al cumplimiento de las obligaciones del Estado contenidas en el instrumento internacional.

Esta teoría la sostienen la antigua Comisión y la Corte Europea de Derechos Humanos y precisan que no implica una franquicia para el Estado, sino que es una consecuencia de la democracia y el pluralismo, y que el tribunal nacional, al conocer su realidad con proximidad, se encuentra en una buena posición para evaluar, en cada caso concreto, los matices en la aplicación del tratado internacional, pero sin transgredir su contenido. Se parte del supuesto de que el tribunal nacional conoce a profundidad las peculiaridades del país y el contexto en el cual los derechos humanos deben ser respetados. Por ningún motivo es un camino para evadir el cumplimiento del tratado. En consecuencia, si no existe control internacional de ese "margen", éste no puede permitirse. ${ }^{29}$

La Corte IDH también se ha referido a esta teoría del "margen de apreciación nacional". Por ejemplo, sostiene que "se trata de valores que adquieren dimensiones concretas a la luz de la realidad a que están llamados a materializarse y que dejan un cierto margen de apreciación para la expresión que deben asumir en cada caso". ${ }^{30}$

29 Sagües, Néstor P., op. cit., pp. 44-49; Nogueira Alcalá, Humberto, La interpretación constitucional de los derechos humanos, Lima, Ediciones Legales, 2009, pp. 42-43; Kastanas, Elías, Unité et diversité: Notions autonomes et marge d'appréciation des états dans la jurisprudence de la Cour Européenne des droits de l'homme, Bruselas, Etablissements Emile Bruyant, 1996, pp. 439 y 440.

30 Corte IDH, Opinión Consultiva 4/84, presentada por Costa Rica, del 19 de enero de 1984, Serie A, núm. 4. 


\section{LA COMISIÓn InTERAMERICANA DE DeReChos Humanos}

18. Regreso a ocuparme del sistema interamericano de derechos humanos, que es el más importante y próximo a México, y el cual puede ser el más trascendente, en virtud del reconocimiento de la competencia contenciosa de la Corte IDH que nuestro país realizó en 1998.

Un buen número de estudiosos del tema están de acuerdo, para efectos didácticos, con identificar la evolución del sistema interamericano de protección de los derechos humanos en cinco etapas fundamentales. ${ }^{31}$

La primera está constituida por los antecedentes del sistema, en donde se encuentra una amalgama de instrumentos internacionales de diverso alcance jurídico, como ciertas convenciones, declaraciones y resoluciones de diverso género, por ejemplo la Declaración Americana de los Derechos y Deberes del Hombre de 1948, acompañada por la Carta Internacional Americana de Garantías Sociales de 1948.

La segunda se encuentra constituida por la formación del sistema interamericano de protección, destacándose aquí el papel fundamental de la Comisión Interamericana de Derechos Humanos (CIDH), creada por la resolución VIII de la V Reunión de Consulta de los Ministros de Relaciones Exteriores que se celebró en Santiago de Chile en 1959.

La tercera evoluciona a partir de la entrada en vigor de la Convención Americana sobre Derechos Humanos, en ella acontece una verdadera institucionalización convencional del sistema. Esto sucede en 1978, con la entrada en vigor de la Convención Americana sobre Derechos Humanos de 1969, la cual "establece" la Comisión y crea la Corte Interamericana de Derechos Humanos como sus órganos de supervisión y decisión, respectivamente.

A partir de entonces la Comisión Interamericana desempeña un doble papel: a) como órgano previsto en la Carta de la OEA para vigilar el cumplimiento de los derechos humanos en los países que no han ratificado la Convención Americana, y b) como órgano de supervisión del cumplimiento de la mencionada Convención en relación con los países ratificantes de la misma.

31 Carpizo, Jorge y Gómez-Robledo, Alonso, op.cit., y en Temas constitucionales, cit., pp. 462 y 463 . 
La cuarta es la consolidación del sistema, desarrollada a partir de la década de los ochenta. En esas fechas se genera una sustancial jurisprudencia de la Corte IDH; se adoptan los dos protocolos adicionales a la Convención Americana: sobre los Derechos Económicos, Sociales y Culturales de 1988, por una parte, y el relativo a la Abolición de la Pena de Muerte de 1990, por la otra.

La quinta está marcada por el perfeccionamiento de la protección de la Convención Americana sobre Derechos Humanos, aunado a los otros sistemas de protección a nivel global (por ejemplo, los dos Pactos de Naciones Unidas sobre Derechos Humanos), en los que existe complementariedad, coordinación y coexistencia. ${ }^{32}$

No cabe la menor duda que con la instauración en 1979 de la Corte IDH, y sobre todo con la posterior ratificación y adhesión a la Convención Americana sobre Derechos Humanos de 1969 por parte de la mayoría de los Estados miembros de la OEA, la CIDH y la Corte IDH se han constituido en los principales órganos encargados de la protección de los derechos humanos en América Latina.

A partir del año 2000 existe un importante esfuerzo para agilizar el procedimiento de quejas individuales tanto ante la Comisión como ante la Corte, lo que ha implicado reformas a los Reglamentos de ambos órganos en diversas ocasiones.

19. El sistema interamericano de protección de los derechos humanos, como ya expresé, cuenta con dos órganos especializados para vigilar el cumplimiento de la Declaración Americana de Derechos y Deberes del Hombre y la Convención Americana sobre Derechos Hu-

32 Véanse los estudios del profesor brasileño Antonio Augusto Cançado Trinidade: a) "El sistema internacional de protección de los derechos humanos (1948-1995). Evolución, estado actual y perspectivas", Derecho internacional y derechos humanos, San José, Costa Rica, San JoséLa Haya, Editores Bardonnet, D. y Cançado, 1996, pp. 47-97; b) "La question de la protection international des droits economiques, sociaux et culturels: evolution et tendences actuelles", Révue Génerale de Droit International Public, París, núm. 94, 1990, pp. 913-946; c) “Co-existence and Co-ordination of Mechanism of International Protection of Human Rights", Recueil des Cours de l'Académie de Droit International, La Haya, 1987, núm. 202, pp. 13-435; Gros Espiell, Héctor, Derechos humanos y vida internacional, México, CNDH-UNAM, Instituto de Investigaciones Jurídicas, 1995, pp. 9-69 y 217-259, y Grossman, Claudio, "Reflexiones sobre el sistema interamericano de protección y promoción de los derechos humanos", La Corte y el sistema interamericano de derechos humanos, San José, Costa Rica, OEA y Unión Europea, 1994, pp. 245-263. 
manos (CADH), a saber: la CIDH, que es un órgano cuasi judicial, una especie de ministerio público y de ombudsman, y la Corte IDH, con dos competencias: una de carácter consultivo y otra de jurisdicción plena o contenciosa.

De ambos órganos he expresado ya algunos conceptos y de la Corte he citado varias de sus resoluciones.

En virtud de la importancia que los dos órganos tienen para el orden constitucional mexicano y en la protección y defensa de los derechos humanos de los habitantes del país, expongo otras nociones sobre ellos, aunque de carácter panorámico.

Recapitulo: en 1959 se creó la CIDH únicamente con atribuciones de divulgación. El Consejo de la OEA aprobó su Estatuto en 1960, y eligió a sus primeros siete miembros. Casi seis años más tarde, la II Conferencia Extraordinaria amplió los poderes de la Comisión para que pudiera recibir denuncias individuales por presuntas violaciones a los derechos humanos. En 1967, con la reforma de la Carta de la OEA, recogida en el Protocolo de Buenos Aires, la Comisión pasó a convertirse en uno de los órganos formales de la propia OEA, con lo cual además, adquirió competencia con respecto a todos los Estados miembros de la Organización ${ }^{33}$.

En otras palabras, a partir de 1960 y durante casi veinticinco años, la CIDH fue el único órgano protector de los derechos humanos en el sistema interamericano; desde 1978 comparte con la Corte IDH la función de dicha protección en este continente.

Es posible que la CIDH, de acuerdo con el Pacto de San José, posea una competencia más amplia que aquella conferida a la Corte.

La CIDH tiene las funciones de: promover la observancia y defensa de los derechos humanos; formular recomendaciones cuando lo estime pertinente a los gobiernos de los Estados miembros para que adopten medidas progresivas en favor de los derechos humanos dentro del mar-

33 Véanse Márquez Rodríguez, Edith, Las relaciones entre la Comisión y la Corte Interamericana de Derechos Humanos, Rafael Nieto Navia, ed., San José, Costa Rica, CIDH, 1994, pp. 297-320; Gómez-Robledo, Alonso, “Atribuciones jurídicas fundamentales de la Comisión Interamericana de Derechos Humanos”, en Fix-Zamudio, Héctor (coord.), México y las declaraciones de derechos humanos, México, Corte IDH-UNAM, Instituto de Investigaciones Jurídicas, 1999, pp. 200-204. 
co de sus preceptos constitucionales; solicitar, de oficio, a los gobiernos de los Estados miembros que le proporcionen informes sobre medidas que adopten en materia de derechos humanos; atender consultas de los Estados miembros y prestarles asesoramiento; realizar visitas in situ; elaborar informes generales o específicos, con las correspondientes recomendaciones, sobre la situación de los derechos humanos en cualquier país del continente; dictar medidas cautelares; una de importancia especial: admitir de cualquier persona, grupo o entidad no gubernamental - legalmente reconocida - las peticiones que contengan denuncias o quejas de violación de la Convención Americana supuestamente realizadas por un Estado parte de la misma; recurrir a la Corte IDH, ${ }^{34}$ y recibir comunicaciones interestatales, es decir, un Estado puede presentar un reclamo contra otro, aunque en este caso ambos Estados deben haber ratificado la Convención Americana y haber aceptado esta facultad de la Comisión Interamericana.

En relación con su función de recibir peticiones de denuncias, la $\mathrm{Co}$ misión es competente en todos los países que aprobaron la Declaración Americana de Derechos y Deberes del Hombre de 1948, aunque no hayan ratificado el Pacto de San José. La CADH, en su artículo 46, señala cuatro requisitos básicos para que se surta esta función de la Comisión: a) que se hayan interpuesto y agotado los recursos de la jurisdicción interna con algunas excepciones; $b$ ) que sea presentada dentro del plazo de seis meses, a partir de la fecha en que se hubiese notificado al presunto lesionado la resolución definitiva en el ámbito interno; c) que la materia de la petición no se encuentre ante otra instancia internacional, y d) que se incluyan los datos de identificación de la persona, grupo o sus representantes. Los dos primeros requisitos pueden ser superados en los casos que el propio artículo 46 señala: cuando en el ámbito interno no exista legislación que garantice el debido proceso legal para la protección del derecho supuestamente violado; no se permitió al presunto lesionado acceso a los recursos de la jurisdicción interna o se le impidió agotarlos, y si existe retardo injustificado en la resolución de esos recursos.

34 Carpizo, Jorge y Gómez-Robledo, Alonso, op. cit., pp. 463 y 464; Ayala Corao, Carlos, "El sistema interamericano de promoción y protección de los derechos humanos", en FixZamudio, Héctor (coord.), México y las declaraciones de derechos humanos, cit., pp. 106-108. 
Las diversas etapas y aspectos del procedimiento tratándose de las peticiones individuales de denuncias y quejas se encuentran regulados en los artículos 48 a 51 de la $\mathrm{CADH},{ }^{35}$ y se pueden sintetizar de la manera siguiente:

a) La CIDH, al recibir la queja o petición, verifica que cumpla con los requisitos para darle trámite, y la transmite al Estado para recabar su posición sobre el asunto.

b) La etapa de admisibilidad tiene por objeto analizar si la petición cumple o no con los extremos señalados por la Convención Americana en el artículo 46, tales como plazo de presentación y agotamiento de recursos.

c) Una vez que la Comisión Interamericana cuenta con los elementos suficientes para pronunciarse sobre la admisibilidad formal de la queja, puede decidir que no cumple con los requisitos y declara su inadmisibilidad, o que sí los satisface y la declara formalmente admitida.

d) La decisión de admisibilidad abre la etapa de fondo y, a su vez, el momento señalado por la Convención Americana para resolver el asunto por vía amistosa, de ser el deseo de las partes.

e) La decisión de fondo es la resolución por la cual la Comisión se pronuncia sobre si existió o no por parte del Estado violación a la Convención Americana, así como las recomendaciones que le dirige para solucionar el asunto.

f) La decisión de fondo de la Comisión consiste en un informe que es confidencial y sólo se envía al Estado involucrado, con un plazo para que atienda las recomendaciones que se le dirigen.

g) Transcurrido ese plazo, y de haber sido satisfechas las recomendaciones a juicio de la Comisión, ésta puede elaborar un segundo informe y, luego de un plazo concedido al Estado para que lo atienda, puede hacerlo del conocimiento público. De decidir la Comisión que no ha lugar a elaborar el mencionado segundo informe,

35 Una síntesis del procedimiento puede verse en Carmona Tinoco, Jorge Ulises, "Algunos aspectos de la participación de México ante los órganos del sistema interamericano de protección de los derechos humanos", Cuestiones Constitucionales. Revista Mexicana de Derecho Constitucional, México, UNAM-Instituto de Investigaciones Jurídicas, 2003, núm. 9, pp. 16-18. 
procede a demandar al Estado ante la Corte IDH, con lo cual inicia el proceso ante ésta.

La CIDH posee una importante atribución en su Reglamento, más no en la Convención, para dictar medidas cautelares en casos urgentes.

20. Las peticiones individuales de mexicanos ante la CIDH han sido y son abundantes, y desde el comienzo de esta función a cargo de la Comisión. En 1966, un año después de que se le atribuyó la facultad de conocer y desahogar peticiones individuales, al rendir su primer Informe Anual, la Comisión señaló que había recibido información del gobierno de México en relación con varias denuncias en las cuales se aducía violación de derechos humanos en el territorio nacional.

No obstante, no fue sino hasta el Informe Anual de 1988 cuando se mencionó el contenido de una resolución definitiva de un caso mexicano, y en el cual la Comisión Interamericana no encontró violación alguna a la CADH por parte de nuestro país.

A partir de entonces, las peticiones de denuncias y quejas han aumentado y en la mayoría de las resoluciones de la Comisión sí se han reconocido violaciones de derechos humanos. Algunos casos han sido notorios por la gravedad de los hechos o por las personas afectadas, como el del vado de Aguas Blancas, en el estado de Guerrero, en que 17 personas fueron ejecutadas extrajudicialmente por policías de ese Estado; los asesinatos de varios periodistas; la extraña muerte de una defensora de derechos humanos; la detención y hostigamiento a un general disidente del ejército mexicano, y la falta de recursos jurídicos que existía para defender la violación de los derechos políticos en las elecciones. ${ }^{36}$

En las soluciones amistosas ante la Comisión, el peticionario y los representantes del Estado demandado entablan pláticas e intercambio de opiniones, con la finalidad de llegar a acuerdos que sean satisfactorios y beneficien al peticionario.

La primera solución amistosa exitosa en relación con México aconteció en diciembre de 2000, con el Informe de la Solución Amistosa núm. 107/00, en el caso 11, 808 sobre la ejecución extrajudicial de una persona por parte de un miembro del ejército mexicano. El acuerdo

36 Ibidem, pp. 25-34. 
que se alcanzó incluyó el ejercicio de la acción penal contra el presunto homicida, quien posteriormente fue encontrado culpable, la indemnización de carácter económico a los familiares de la víctima y apoyos económicos a la viuda e hijos menores de edad hasta que alcanzaran la mayoría de edad. Otros casos han seguido a éste.

La CIDH ha decretado medidas cautelares en casos graves, que generalmente están relacionados con situaciones en que se encuentra en peligro la vida o la integridad personal. México ha respondido afirmativamente y con diligencia, aunque no siempre los resultados han sido exitosos.

El gobierno de México invitó a la Comisión para que realizara una visita in situ para examinar la situación de los derechos humanos en el país, la cual se efectuó en julio de 1996. Fue la primera vez que algo similar acontecía en la Nación. El 24 de septiembre de 1998, la CIDH dio a conocer el resultado definitivo de dicha visita, y formuló 61 recomendaciones al gobierno mexicano sobre el derecho a la vida, a la libertad personal, a la integridad personal, a la justicia, derechos políticos, situación y derechos de los pueblos indígenas, derechos económicos, sociales y culturales, derechos de la mujer y libertad de expresión.

\section{LA CORTE INTERAMERICANA DE DERECHOS Humanos Y EL CONTROL DIFUSO DE CONVENCIONALIDAD}

21. La Corte IDH es un órgano no permanente, cuya sede se encuentra en San José, Costa Rica, aunque puede celebrar sesiones en otras ciudades.

La Corte IDH se integra por siete jueces, nacionales de los Estados miembros de la OEA, que son electos a título personal por la Asamblea General de la OEA, en votación secreta, a propuesta de los Estados partes de la Convención Americana y no es necesario que sea nacional del Estado proponente, pero no puede haber dos jueces de la misma nacionalidad. 
El periodo del juez es por seis años y es susceptible de ser reelecto únicamente en una ocasión. ${ }^{37}$

22. Edith Márquez, señala que la Corte IDH:

Fuera de su competencia administrativa y presupuestaria... el ejercicio de las competencias judiciales, tanto consultiva como contenciosa, que la Convención le confió, depende de decisiones que previamente deben adoptar principalmente los Estados o la Comisión, sin que la Corte esté capacitada para emprender iniciativas tendientes a proteger los derechos humanos sin haber sido expresamente requerida para ello. ${ }^{38}$

La Corte IDH, a semejanza de la Corte Internacional de Justicia de La Haya, posee una fase consultiva y una contenciosa.

Así, la Corte IDH puede emitir opiniones consultivas, a petición de los Estados miembros de la OEA, de los órganos principales de la Carta [capítulo X], y de la CIDH sobre cuestiones referentes fundamentalmente a la interpretación del Pacto de San José, o de otros tratados concernientes a la protección de los derechos humanos en los Estados americanos, así como de la compatibilidad de las legislaciones internas de los Estados —a solicitud expresa de ellos mismos (artículo 64, párrafo 29) - y los instrumentos internacionales de derechos humanos.

Los dictámenes o fallos emitidos por la Corte IDH en su fase consultiva carecen de fuerza jurídica vinculante, pero poseen una gran autoridad, no sólo moral, sino doctrinaria, y por lo general se convierten en punto de referencia imprescindible y constante en su jurisprudencia.

En la fase consultiva no se trata de solucionar una controversia sino, fundamentalmente, de realizar una "interpretación" del derecho en cuestión. ${ }^{39}$

37 Martín, Claudia, "La Corte Interamericana de Derechos Humanos: funciones y competencia”, en Martín Claudia et al. (comps.), Derecho internacional de los derechos humanos, México, Universidad Iberoamericana-Fontamara, 2006, pp. 209-217.

38 Márquez Rodríguez, Edith, op. cit., p. 302.

39 Fix-Zamudio, Héctor, Protección de los derechos humanos: estudios comparativos, México, CNDH, 1991, pp. 167-186; id., "Lineamientos procesales de los procedimientos ante la Corte Interamericana de Derechos Humanos", en Nieto Navia, Rafael (ed.), La Corte y el sistema interamericano de derechos humanos, San José, OEA-Unión Europea, 1994, pp. 147-189. 
Así lo ha precisado con claridad la misma Corte:

En materia consultiva, la Corte no está llamada a resolver cuestiones de hecho para verificar su existencia, sino a emitir su opinión sobre la interpretación de una norma jurídica. La Corte, en este ámbito, cumple una función asesora, de tal modo que sus opiniones no tienen el mismo efecto vinculante que se reconoce para sus sentencias en materia contenciosa. ${ }^{40}$

No obstante, la propia Corte les puede otorgar fuerza jurídica vinculante al actuar o seguir ese criterio en el futuro; por ejemplo, ya no existe la figura del juez ad hoc para los casos contenciosos, en razón de la opinión consultiva 20/09, que solicitó Argentina, aunque sí subsiste para la integración de la Corte Interamericana cuando no existe un juez de su nacionalidad, pero únicamente si el caso contencioso es entre Estados partes o si varios Estados partes tienen un mismo interés en el caso, entonces se consideran como una sola parte. Esta interpretación la dedujo la Corte IDH del artículo 55, incisos 2 y 5 del Pacto de San José, siempre y cuando los Estados partes hubiesen declarado aceptar esa competencia de la Corte.

23. De acuerdo con el Pacto de San José de 1969, solamente los Estados partes y la CIDH poseen el derecho de someter un caso a la decisión de la Corte IDH. Queda claro que las personas privadas o particulares no poseen un derecho de acceso a la jurisdicción contenciosa, esto es, carecen de locus standi. ${ }^{41}$

La jurisdicción de la Corte IDH es de naturaleza excepcional, subsidiaria y complementaria de aquella del orden interno.

24. El solo hecho de que un Estado sea parte de la CADH no es suficiente para conferirle jurisdicción automática a la Corte, sino que necesariamente se requiere de un acto adicional de sometimiento expreso a su jurisdicción, el cual puede presentarse ya sea mediante el

40 Corte IDH, "Otros tratados, objeto de la función consultiva de la Corte, artículo 64, Convención Americana de Derechos Humanos”, Opinión Consultiva, OC-1/82, del 24 de septiembre de 1982, Serie A, núm. 1, párr. 51.

${ }^{41}$ Salgado Pesantes, Hernán, "La Corte Interamericana de Derechos Humanos: naturaleza y funciones”, en Héctor Fix-Zamudio, (coord.), México y las declaraciones de..., cit., pp. 161164. 
consentimiento otorgado antes de que surja la controversia (jurisdicción compulsoria), o bien mediante el consentimiento otorgado después de que ha surgido el diferendo (jurisdicción voluntaria).

El artículo 62 de la CADH es muy claro a este respecto:

1. Todo Estado parte puede, en el momento del depósito de su instrumento de ratificación o adhesión de esta Convención, o en cualquier momento posterior, declarar que reconoce como obligatoria de pleno derecho y sin convención especial, la competencia de la Corte, sobre todos los casos relativos a la interpretación o aplicación de esta Convención.

2. La declaración puede ser hecha incondicionalmente, o bajo condición de reciprocidad, para un plazo determinado o para casos específicos...

3. La Corte tiene competencia para conocer de cualquier caso relativo a la interpretación y aplicación de las disposiciones de esta Convención que le sea sometido, siempre que los Estados parte en el caso, hayan reconocido o reconozcan dicha competencia, sea por declaración especial, ... sea por convención especial.

\section{El artículo 28 del Estatuto de la Corte IDH indica que la CIDH} comparecerá y será tenida como parte en todos los casos relativos a la función jurisdiccional de aquélla. Debe quedar claro que no existe una presunta "automaticidad" en el envío de los casos a la Corte, una vez que ha sido concluido el procedimiento ante la Comisión; es decir, cuando se haya rendido el informe respectivo, y que no se pudo encontrar una solución amistosa.

Para que la CIDH esté en posibilidades de someter un caso ante la Corte, de la práctica interamericana se pueden desprender ciertas condiciones o requisitos, que son "condiciones mínimas", para que un affaire sea sometido a la Corte IDH.

Se puede afirmar que el primer requisito es que el Estado afectado haya aceptado la jurisdicción obligatoria de la Corte IDH, de la manera que fuese; es decir, antes de que nazca la controversia, o después de ella para el caso específico. En segundo término, que haya existido por parte del Estado, en contra del cual se somete el caso, una violación a un derecho humano garantizado por la Convención Americana; esto es, si se ha agotado el procedimiento ante la Comisión y ésta decidió que no encontró violación a los derechos humanos, carecería de todo sentido someter el caso a la Corte. 
Además, como tercera condición, parece ser que el criterio para la remisión de un caso a la Corte consiste en que se puedan tutelar de manera más efectiva los derechos humanos protegidos por la Convención de San José de Costa Rica. ${ }^{42}$

26. El artículo 63.2 de la CADH señala la posibilidad de que la Corte dicte medidas precautorias:

En caso de extrema gravedad y urgencia, y cuando se haga necesario evitar daños irreparables a las personas, la Corte, en los asuntos que esté conociendo, podrá tomar las medidas provisionales que considere pertinentes. Si se tratare de asuntos que aún no estén sometidos a su conocimiento, podrá actuar a solicitud de la Comisión.

27. El procedimiento comprende una fase escrita y una oral.

El proceso comienza con el informe de fondo (demanda) que presenta la CIDH, y al cual se refiere el artículo 50 del Pacto de San José. Es decir, se somete el caso a la jurisdicción de la Corte.

El proceso ante la Corte Interamericana ha sufrido cambios de fondo con el Reglamento de 2009, que entró en vigor el 1o. de enero de 2010, para darle una mayor participación a las presuntas víctimas.

El informe de fondo de la CIDH debe contener todos los hechos supuestamente violatorios y la identificación de las presuntas víctimas. Para que la Corte pueda examinar el caso debe recibir diversas informaciones que indica el artículo 35 y entre ellas los nombres de los delegados (los representantes de la Comisión), los motivos por los cuales se somete ese caso a su jurisdicción, sus observaciones a la respuesta del Estado demandado con relación a las recomendaciones que le hizo, copia de la totalidad del expediente ante la Comisión, todas las pruebas que recibió, y las pretensiones incluidas las reparaciones.

42 Véase en este sentido la opinión consultiva sobre "Ciertas atribuciones de la Comisión Interamericana de Derechos Humanos”, Corte IDH, opinión consultiva núm. 13/93, párr. 50. Es interesante señalar que en la Conferencia Especializada sobre Derechos Humanos en 1969, el relator de la II Comisión consideró que la Comisión podría desempeñar ante la Corte una función similar a la que correspondería al Ministerio Público, en el sentido de que estaría representado no sólo el interés general del sistema de la Convención, sino también los intereses de las víctimas, que no tenían en aquel entonces, como tales, acceso directo a la jurisdicción de la Corte. Actas y Documentos, Washington, Doc. OEA y SER.K/XVI 1.2, 1973. 
El artículo 36 señala los requisitos del escrito correspondiente, si el sometimiento del caso es por parte de un Estado.

De acuerdo con el artículo 25.1 del Reglamento actual, después de notificado el escrito de sometimiento del caso, las "presuntas víctimas o sus representantes podrán presentar de forma autónoma su escrito de solicitudes, argumentos y pruebas y continuarán actuando de esa forma durante todo el proceso".

Una vez notificadas las presuntas víctimas o sus representantes disponen de un plazo improrrogable de dos meses, a partir de la recepción de esa notificación, para la presentación autónoma de su escrito de solicitudes, argumentos y pruebas.

Cuando las notificaciones ya se han realizado, y dentro del plazo previsto, se pueden oponer "excepciones preliminares" - que realmente constituyen excepciones dilatorias y presupuestos procesales-, como son, entre otras, la propia competencia de la Corte, el agotamiento de los recursos internos o las condiciones de admisibilidad. ${ }^{43}$

El Estado demandado debe contestar por escrito su posición tanto del informe de la CIDH como del escrito de solicitudes de las presuntas víctimas, si es el caso.

Después de la contestación del Estado, las partes pueden gestionar la admisión de documentos y si la presidencia de la Corte acepta la petición, fijará el plazo para su presentación.

28. Dentro del procedimiento oral, la presidencia fija el número de audiencias necesarias para el desahogo de testigos, declarantes y peritos en su caso. Todos ellos pueden ser interrogados tanto por los jueces como por los representantes de las partes. El capítulo III del Reglamento se refiere al procedimiento oral.

En la audiencia, en primer término, la CIDH debe exponer los fundamentos de su informe de fondo y cualquier asunto que considere pertinente al caso.

Terminado el procedimiento oral, el Estado demandado y las presuntas víctimas y sus representantes tienen la oportunidad de presentar alegatos finales escritos en el plazo que determine la presidencia.

43 Cançado Trinidade, Antonio Augusto, The Aplication of the Rule of Exhaustion of Local Remedies in the International Law, Cambridge, Cambridge University Press, 1983, pp. 1-42. 
La CIDH puede, asimismo, ofrecer observaciones finales escritas.

29. Aunque la Convención Americana no señala en el procedimiento la intervención de los individuos - generalmente la víctima o sus representantes - desde los primeros tiempos de la Corte Interamericana, la CIDH designó a aquellos como sus asesores, y así podían intervenir en el juicio como parte del equipo de la Comisión, y su contribución generalmente fue muy activa. En la actualidad, con el Reglamento de 2010 las presuntas víctimas y sus representantes han adquirido independencia de la CIDH durante el procedimiento ante la Corte; incluso pueden señalar violaciones adicionales en sus argumentos, diversas a aquellas que se alegan en la demanda de la Comisión, pero basadas en los hechos de la demanda de ésta, no en hechos distintos. ${ }^{44}$

30. Una vez terminadas estas etapas, la Corte IDH dicta sentencia; ésta debe ser debidamente motivada, y cualquiera de los siete jueces puede acompañar el fallo con una opinión individual, o con una opinión disidente, según sea el caso, y sin olvidar que si entre los jueces llamados a conocer de aquél, ninguno fuere de la nacionalidad de los Estados parte, cada uno de ellos podrá designar un juez ad hoc pero exclusivamente si se trata de una petición interestatal, como ya asenté.

De acuerdo con esa Convención, si la Corte IDH llega a la decisión de que existió una violación de un "derecho o libertad protegidos" por la Convención, la Corte dispone que se garantice al lesionado en el goce de su derecho o libertad conculcados.

De igual suerte, y si fuere procedente, la Corte está facultada para señalar que se repare el daño ocasionado, esto es, puede ordenar que se realice una restitutio in integrum, o si fuere posible, entonces ordenar la reparación del daño, ya sea a través de una medida de indemnización a la parte lesionada, u otras que se consideren procedentes (artículo 63).

31. El fallo que dicta la Corte Interamericana tiene carácter definitivo y es inapelable. La Corte admite únicamente el "recurso de inter-

${ }^{44}$ Fix-Zamudio, Héctor y Valencia Carmona, Salvador, Derecho constitucional mexicano y comparado, México, Porrúa-UNAM, Instituto de Investigaciones Jurídicas, 2009, pp. 575-578; Martin, Claudia, op. cit., pp. 223-228; véanse Corte IDH, Caso Garibaldi vs. Brasil. Excepciones preliminares, Reparaciones y Costas, resolución del 23 de septiembre de 2009, Serie C, núm. 203, párr. 59, y Caso González y otras (“Campo Algodonero") vs. México, Excepción preliminar, Fondo, Reparaciones y Costas, resolución del 16 de noviembre de 2009, Serie C, núm. 205, párr. 232. 
pretación", que procede sólo en caso de desacuerdo sobre el sentido o alcance de la resolución, siempre y cuando se solicite en el plazo de noventa días a partir de la fecha de la notificación del mismo. ${ }^{45}$

Los Estados parte están obligados a cumplir con las resoluciones de la Corte IDH, lo cual responde a lógica pura: si no esa Corte de tribunal nada tendría, los Estados incumplirían con sus obligaciones internacionales a voluntad y el sistema interamericano de derechos humanos estaría lisiado y deforme si un Estado pudiera desobedecer una sentencia del órgano cúspide del sistema. Entonces, dicho sistema serviría únicamente de oropel.

El artículo 68 de la CADH es definitivo: los Estados están comprometidos a cumplir la resolución de la Corte Interamericana en los casos en que sean parte. La propia Corte así lo ha establecido en reiteradas jurisprudencias. ${ }^{46}$

32. El párrafo 2 del mencionado artículo 68 establece que la parte de la sentencia que condena al pago de una indemnización compensatoria habrá de ejecutarse en el país sancionado, por el mismo procedimiento interno establecido para la ejecución de sentencias contra el Estado. El

45 No debe extrañar que muchas de las disposiciones que se encuentran para la organización y procedimiento de la Corte IDH se encuentran, mutatis mutandis, en el Estatuto de la Corte Internacional de Justicia, Así, por ejemplo, el Estatuto de esta última también contempla la figura del juez ad hoc (artículo 31, párrafos 2 y 3); el procedimiento consta igualmente de una fase escrita y otra oral; esta última consistente en una audiencia que la Corte otorga a testigos, peritos, agentes, consejeros y abogados (artículo 43, párráfos 1 al 5); las sentencias conllevan, de la misma forma, un análisis de los hechos, síntesis de argumentos de una y otra parte, exposición de motivos y argumentación jurídica, y las conclusiones, que vienen a ser la parte dispositiva propiamente dicha. Los jueces pueden anexar sus opiniones disidentes cuando el desacuerdo se refiere a la parte dispositiva, o bien anexar sus opiniones individuales cuando su desacuerdo hace referencia al razonamiento de la Corte, pero coinciden con sus conclusiones (artículo 57 del Estatuto de la Corte Internacional de Justicia). El fallo es igualmente definitivo e inapelable, y se acepta el "recurso de interpretación", en caso de desacuerdo sobre el alcance de la sentencia (artículo 60 del Estatuto), etcétera. Los jueces de la Corte Interamericana son electos por un periodo de seis años, con posibilidad de reelección por una sola vez, en tanto que los jueces de la Corte de La Haya son electos por un periodo de nueve años, con posibilidad de reelección (artículos 54 y 13, respectivamente).

46 Por ejemplo, Corte IDH, Caso Loayza Tamayo, Cumplimiento de sentencia, resolución del 17 de noviembre de 1999, Serie C, núm. 60, considerando 7; Corte IDH, Caso Castillo Petruzzi y otro, Cumplimiento de sentencia, resolución del 17 de noviembre de 1999, Serie C, núm. 59, considerando 4 . 
problema estriba en que dichos procedimientos son casi inexistentes o ineficaces en América Latina. Por esta razón, la Corte IDH decidió acertadamente la aplicación directa del derecho internacional y, en consecuencia, en sus propias sentencias estableció la forma y los plazos en que la resolución debe ser cumplida por el Estado infractor.

33. El artículo 65 de la CADH señala que la Corte en su informe anual a la Asamblea General de la OEA debe indicar el Estado y el caso cuya sentencia no ha sido cumplida.

El sistema interamericano no cuenta como el europeo con un sistema de vigilancia del cumplimiento de sus sentencias, como es el Comité de Ministros del Consejo de Europa; la experiencia demuestra que la Asamblea General de la OEA no es el órgano idóneo para tal finalidad. ${ }^{47}$

En el sistema interamericano hay que reflexionar al respecto y crear un mecanismo eficaz para el cumplimiento de las resoluciones de la Corte IDH.

Dicho cumplimiento no puede dejarse exclusivamente al orden jurídico interno y a la voluntad de los gobernantes en turno, incluso ni cuando la Constitución del Estado contenga normas para la ejecución de decisiones de los órganos internacionales, como es el caso del artículo 31 de la Constitución de Venezuela, pero en la realidad el gobierno de dicho país, ante normas internas que violan la $\mathrm{CADH}$, alega que la intervención de los órganos del sistema interamericano viola su soberanía interna..$^{48}$

34. La jurisprudencia de la Corte IDH es obligatoria para los Estados que reconocen su competencia contenciosa, porque es la interpretación de última instancia de la CADH. Los casos concretos que conoce la Corte son importantes pero son relativos a un país determinado, y aún el número de asuntos que resuelve no es numeroso. En cambio, la jurisprudencia de la Corte está creando un Ius Commune de protección

47 Fix-Zamudio, Héctor, Los derechos humanos y su protección internacional, Lima, Grijley, 2009 , pp. 60-65.

48 Véanse Carmona Tinoco, Jorge Ulises, "El marco jurídico e institucional mexicano para atender las recomendaciones de la Comisión Interamericana de Derechos Humanos y cumplir con las sentencias de la Corte Interamericana de Derechos Humanos”, Derecho internacional de los derechos humanos. Culturas y sistemas jurídicos comparados, México, UNAM, Instituto de Investigaciones Jurídicas, 2008, t. I, 335-396 pp.; Fix-Zamudio, Héctor, La creciente internacionalización de las Constituciones iberoamericanas..., cit., pp. 154-158 y 163. 
de los derechos humanos en América Latina y el Caribe, al establecer criterios generales de interpretación de la $\mathrm{CADH}$ que deben respetar todas las autoridades de los países correspondientes. Esa jurisprudencia se invoca cada día más en los tribunales nacionales, pero aún el camino a recorrer es largo. ${ }^{49}$

La Corte IDH ha establecido jurisprudencia precisa al respecto. Por ejemplo:

... el Poder Judicial debe ejercer una especie de "control de convencionalidad" entre las normas jurídicas internas que aplican en los casos concretos y la Convención Americana sobre Derechos Humanos. En esta tarea, el Poder Judicial debe tener en cuenta no solamente el tratado, sino también la interpretación que del mismo ha hecho la Corte Interamericana, intérprete última de la Convención Americana. ${ }^{50}$

... cuando el Legislativo falla en su tarea de suprimir y/o no adoptar leyes contrarias a la Convención Americana, el Judicial permanece vinculado al deber de garantía establecido en el artículo 1 (1) de la misma y, consecuentemente, debe abstenerse de aplicar cualquier normativa contraria a ella”, y los jueces están obligados a velar que se cumplan las disposiciones de la Convención ${ }^{51}$.

35. Por las razones expuestas no existe duda alguna de la obligatoriedad de la jurisprudencia de la Corte IDH para todas las autoridades

49 Caballero Ochoa, José Luis, "La Corte Interamericana de Derechos Humanos frente a los tribunales nacionales. Algunas reflexiones sobre el caso mexicano”, Recepción nacional del derecho internacional de los derechos humanos y admisión de la competencia contenciosa de la Corte Interamericana, cit., pp. 324-326; Silva García, Fernando, Derechos humanos. Efectos de las sentencias internacionales, México, Porrúa, 2007, pp. 130-199; Carpizo, Jorge, "Prólogo", en von Bogdandy, Armin et al. (coords.), La justicia constitucional y su internacionalización. ¿Hacia un Ius Constitutionale Commune en América Latina?, México, UNAM, Instituto de Investigaciones Jurídicas-Max-Planck-Institut für ausländisches öffentliches Recht und Völkerrecht-Instituto Iberoamericano de Derecho Constitucional, 2010, pp. XX y XXI; Carmona, Jorge, La recepción de la jurisprudencia de la Corte Interamericana de Derechos Humanos en el ámbito interno..., cit., pp. 264-266.

50 Corte IDH, Caso Almonacid Arellano, sentencia del 26 de septiembre de 2006, Serie C, núm. 154, párr. 124.

51 Ibidem, párr. 121. Véase Nogueira Alcalá, Humberto, op. cit., pp. 37-41, en relación con tesis jurisprudenciales de cortes y tribunales constitucionales latinoamericanos que expresamente aceptan la importancia y la obligatoriedad de la jurisprudencia de la Corte IDH. 
de un Estado parte de la Convención Americana que hayan aceptado la competencia contenciosa de la Corte, y el desarrollo de esta obligatoriedad es lógico y congruente con las características de los derechos humanos.

En el párrafo 124 de la sentencia del Caso Almonacid Arellano, que cité en el numeral anterior, la Corte IDH se refirió a que el Poder Judicial debe ejercer una especie de control de convencionalidad. Era septiembre de 2006, fecha bastante reciente. Estaba naciendo dicho control en forma tímida, y es natural porque se estaba innovando y perfeccionando en forma espléndida el sistema interamericano. Y digo que era una expresión tímida, debido a que se refirió a "una especie" (énfasis mío) y en términos generales al Poder Judicial, pero éste fue un paso histórico, y como pocos, en la protección de los derechos humanos en el mencionado sistema interamericano.

Dos meses posteriores a dicha sentencia, la Corte IDH dictaba otra, en la cual reiteraba la tesis del Caso Almonacid Arellano, y avanzaba en el mencionado control: a) desapareció la expresión "una especie”, quedaba claro que es un verdadero control de convencionalidad, sin adjetivo alguno; es decir, el primer paso tímido se esfumó, ya es un segundo paso dado con toda seguridad; b) los jueces, así: los jueces, están obligados a realizar ese control, en virtud de que están obligados a velar por el pleno "efecto útil" de la Convención y a no permitir que leyes contrarias a ella mermen o anulen su ámbito protector; c) en consecuencia, ese control debe hacerse de oficio cuando así proceda y también por solicitud de parte, $\mathrm{y} d$ ) deben considerarse otros presupuestos formales y materiales de admisibilidad y procedencia. ${ }^{52}$

Esta jurisprudencia, a partir de esos dos casos, se ha reiterado en forma constante. En poco más de cinco años, la Corte IDH la incorporó en trece sentencias de fondo, ${ }^{53}$ además de las resoluciones de supervisión de sentencia y ampliación de medidas provisionales.

52 Corte IDH, Caso Trabajadores Cesados del Congreso (Aguado Alfaro y otros) vs. Perú. Excepciones preliminares, Fondo, Reparaciones y Costas, sentencia del 24 de noviembre de 2006, Serie C, núm. 158, párr. 128.

53 Caso La Cantuta vs. Perú. Fondo, Reparaciones y Costas, sentencia del 29 de noviembre de 2006, Serie C, núm. 162, párr. 173. 


\section{En el Caso Cabrera García y Montiel Flores, ${ }^{54}$ la Corte IDH avanzó}

a pasos de gigante y ha creado el control difuso de convencionalidad. Eduardo Ferrer Mac-Gregor, quien se desempeñó como juez ad hoc en

Caso Boyce y otros vs. Barbados. Excepción preliminar, Fondo, Reparaciones y Costas. Sentencia del 20 de noviembre de 2007, Serie C, núm. 169, párr. 79.

Caso Heliodoro Portugal vs. Panamá. Excepciones preliminares, Fondo, Reparaciones y Costas. Sentencia del 12 de agosto de 2008, Serie C, núm. 186, párr. 180.

Caso Rosendo Radilla Pacheco vs. Estados Unidos Mexicanos. Excepciones preliminares, Fondo, Reparaciones y Costas. Sentencia del 23 de noviembre de 2009, Serie C, núm. 209, párr. 339.

Caso Manuel Cepeda Vargas vs. Colombia. Excepciones preliminares, Fondo, Reparaciones y Costas. Sentencia del 26 de mayo de 2010, Serie C, núm. 213, párr. 208.

Caso Comunidad Indígena Xákmok Kásek vs. Paraguay. Fondo, Reparaciones y Costas. Sentencia del 24 de agosto de 2010, Serie C, núm. 214, párr. 311.

Caso Fernández Ortega y Otros vs. México. Excepción preliminar, Fondo, Reparaciones y Costas. Sentencia del 30 de agosto de 2010, Serie C, núm. 215, párr. 234.

Caso Rosendo Cantú y Otra vs. México. Excepción preliminar, Fondo, Reparaciones y Costas. Sentencia del 31 de agosto de 2010, Serie C, núm. 216, párr. 219.

Caso Ibsen Cárdenas e Ibsen Peña vs. Bolivia. Fondo, Reparaciones y Costas. Sentencia del 1o. de septiembre de 2010, Serie C, núm. 217, párr. 202.

Caso Vélez Loor vs. Panamá. Excepciones preliminares, Fondo, Reparaciones y Costas. Sentencia del 23 de noviembre de 2010, Serie C, núm. 218, párr. 287.

Caso Gomes Lund y Otros (Guerrilha do Araguaia) vs. Brasil. Excepciones preliminares, Fondo, Reparaciones y Costas. Sentencia del 24 de noviembre de 2010, Serie C, núm. 219, párr. 106.

Caso Cabrera García y Montiel Flores vs. México. Excepciones preliminares, Fondo, Reparaciones y Costas. Sentencia del 26 de noviembre de 2010, Serie C, núm. 220, párr. 225.

Caso Gelman vs. Uruguay. Fondo y Reparaciones. Sentencia del 24 de febrero de 2011, Serie C, núm. 221, párrs. 193, 194 y 239.

54 Es el párrafo 225, citado en la nota anterior:

“225. Este Tribunal ha establecido en su jurisprudencia que es consciente que las autoridades internas están sujetas al imperio de la ley y, por ello, están obligadas a aplicar las disposiciones vigentes en el ordenamiento jurídico. Pero cuando un Estado es Parte de un tratado internacional como la Convención Americana, todos sus órganos incluidos sus jueces, también están sometidos a aquél, lo cual les obliga a velar porque los efectos de las disposiciones de la Convención no se vean mermados por la aplicación de normas contrarias a su objeto y fin. Los jueces y órganos vinculados a la administración de justicia en todos los niveles están en la obligación de ejercer ex officio un "control de convencionalidad" entre las normas internas y la Convención Americana, evidentemente en el marco de sus respectivas competencias y de las regulaciones procesales correspondientes. En esta tarea, los jueces y órganos judiciales vinculados a la administración de justicia deben tener en cuenta no solamente el tratado, sino también la interpretación que del mismo ha hecho la Corte Interamericana, intérprete última de la Convención Americana”. 
dicho caso, resaltó los aspectos sobresalientes de la resolución, a saber: a) se reitera que el control de convencionalidad lo deben realizar todos los órganos del Estado para la plena efectividad protectora de la Convención Americana; $b$ ) los jueces y órganos vinculados a la administración de justicia de todos los niveles están obligados a realizar tal control, y todos son todos, sin importar su jerarquía, grado, o cualquier otro aspecto; c) en consecuencia, se crea el control difuso de convencionalidad; d) existe una internacionalización del derecho constitucional, al "trasladar las 'garantías constitucionales' como instrumentos procesales para la tutela de los derechos fundamentales y salvaguarda de la 'supremacía constitucional', a las 'garantías convencionales'” para tutelar los derechos humanos reconocidos en los tratados cuando el orden interno no ha sido eficaz para protegerlos; e) con lo cual se configura una "supremacía convencional”; f) la Corte IDH conserva su calidad de intérprete de última instancia de la CADH; g) en consecuencia, la Corte Interamericana tiene la facultad de examinar si el juez nacional ejerció con acierto o no dicho control, y $h$ ) éste toma en cuenta la competencia del juez, así como las regulaciones procesales correspondientes, aspecto al que ya me he referido. ${ }^{55}$

37. Un tema muy importante al que ya aludí, pero considero que merece una reflexión adicional, es si la Corte IDH posee competencia para conocer alguna violación de un derecho humano no protegido en la Convención Americana, cuyo artículo 62.3 es tajante: "Tiene competencia para conocer de cualquier caso relativo a la interpretación y aplicación de las disposiciones de esta Convención”.

La Corte IDH realizó una interpretación restrictiva de esas facultades. ${ }^{56}$ No obstante, unos meses antes había admitido que sí podía recurrir a otros tratados internacionales de derechos humanos, como pieza de un comprensivo corpus juris internacional que auxilia en el discernimiento del contenido y los alcances de una norma de la Convención Americana..$^{57}$

55 Ferrer Mac-Gregor, Eduardo, Voto razonado del juez ad hoc en relación con..., cit., pp. 4, 8,9 y 15 .

56 Corte IDH, Caso Las Palmeras, Excepciones preliminares, sentencia del 4 de febrero de 2000, Serie C, núm. 67, párrs. 32 y 33.

57 Corte IDH, Caso de los "Niños de la Calle"(Villagrán Morales y Otros), sentencia del 19 de noviembre de 1999, Serie C, núm. 63, párr. 194. 
La propia evolución y madurez, así como el fortalecimiento de su prestigio, le ha permitido ampliar su visión y garantizar el cumplimiento de otros tratados de derechos humanos, aprobados por la Asamblea General de la OEA. Algunos de ellos pareciera que sí le otorgan dicha competencia. La Corte IDH, en principio, se inclina por una respuesta positiva; ${ }^{58}$ considero que realiza una interpretación acertada puesto que: a) cuando se aprobó el Pacto de San José en 1969, era imposible visualizar el desarrollo que la protección de los derechos humanos iba a tener en el sistema interamericano, así como las convenciones que sobre la materia aprobaría la Asamblea General de la OEA, y que forman una unidad; $b$ ) el sistema de protección se perfecciona y amplía, y resulta ilógico que se aprueben nuevos instrumentos de protección y no exista el correspondiente órgano de vigilancia; c) algunas de esas convenciones son de una gran importancia y se refieren a graves problemas en el continente americano, como el Protocolo Adicional a la Convención Americana sobre Derechos Humanos en materia de Derechos Económicos, Sociales y Culturales; la Convención Interamericana para Prevenir, Sancionar y Erradicar la Violencia contra la Mujer, y la Convención Interamericana sobre Desaparición Forzada de Personas, y hay que asegurar su cumplimiento.

38. La Corte IDH está inundada de asuntos. Al respecto, se puede proponer, y considero que la hora ha llegado, que se convierta en un órgano permanente, que se aumente su número a 9 u 11 jueces, quienes puedan desahogar las audiencias y, llegado el caso, que a la Corte se le dote de una especie de writ of certiorari para que resuelva asuntos paradigmáticos que establezcan jurisprudencia, la cual, como debe ser y es, obliga a todas las autoridades de los Estados partes que han reconocido su jurisdicción.

No desconozco que la Corte Interamericana se enfrenta a grandes desafíos, debido a su limitado presupuesto, a la cantidad de asuntos que se le someten y a los retos que le implica la implantación del nuevo Reglamento de 2010; sin embargo, la Corte ha logrado, en los últimos años, reducir el tiempo de trámite de los casos contenciosos a dos años en promedio, a pesar de que las reformas realizadas tanto en los reglamentos

58 Martin, Claudia, op. cit., pp. 229 y 230. 
de la Comisión como en el suyo, aumentaron la cantidad de casos que la Corte atendió.

El problema se encuentra en la verificación del cumplimiento de la sentencia, porque los casos no se cierran en tanto la Corte no considera que se ha cumplido satisfactoriamente su sentencia, sobre todo en lo referente a reparaciones.

\section{MéXICO y la Corte InTeramericana de Derechos Humanos}

39. Expongo algunos aspectos precisos en relación con México y la Corte IDH:

a) Como ya asenté, nuestro país reconoció la competencia contenciosa de la Corte hasta el 16 de diciembre de 1998, y con tal motivo declaró:

I. Los Estados Unidos Mexicanos reconocen como obligatoria de pleno derecho, la competencia contenciosa de la Corte Interamericana de Derechos Humanos, sobre los casos relativos a la interpretación o aplicación de la Convención Americana de Derechos Humanos, de conformidad con el artículo 62.1 de la misma, a excepción de los casos derivados de la aplicación del artículo 33 de la Constitución Política de los Estados Unidos Mexicanos. 2. La aceptación de la competencia contenciosa de la Corte Interamericana de Derechos Humanos solamente será aplicable a los hechos o a los actos jurídicos posteriores a la fecha del depósito de esta declaración, por lo que no tendrá efectos retroactivos. 3. La aceptación de la competencia contenciosa de la Corte Interamericana de Derechos Humanos se hace con carácter general y continuará en vigor hasta un año después de la fecha en que los Estados Unidos Mexicanos notifiquen que la han denunciado.

b) Con anterioridad a dicha declaración México había tenido presencia en la Corte IDH al apoyar o activar el trámite de varias opiniones consultivas, incluso participando en alguna audiencia pública. Después de diciembre de 1998, el país solicitó las opiniones consultivas OC-16 y OC-18, relativas al debido proceso legal en casos de pena de muerte, 
en octubre de 1999, y a la vigencia de los derechos de los migrantes, en septiembre de 2003, respectivamente. ${ }^{59}$

c) La Corte IDH ha dictado medidas provisionales y de carácter urgente para proteger la vida y la integridad de diversas personas por considerar que sus derechos humanos estaban en peligro, como en el caso de varios miembros del Centro de Derechos Humanos "Miguel Agustín Pro Juárez". ${ }^{60}$

d) El primer caso mexicano que conoció esa Corte, después del reconocimiento de su competencia contenciosa por parte de nuestro país, se presentó ante ella en enero de 2003 y fue el de Alfonso Martín del Campo Dodd, por hechos acontecidos el 30 de mayo de 1992, quien supuestamente fue sometido a torturas y otros tratos crueles, inhumanos y degradantes por policías judiciales de la Ciudad de México, con la finalidad de hacerle confesar el asesinato de su hermana y cuñado, acontecido la noche anterior; se suponía que continuaba arbitrariamente privado de su libertad.

La Corte IDH resolvió el asunto el 3 de septiembre de 2004, en el sentido de declarar procedente la excepción ratio temporis alegada por México, en virtud de que los hechos relatados en la demanda ocurrieron con anterioridad a que el país reconociera la competencia contenciosa de la Corte. De esta manera dicho Tribunal no se abocó a conocer el fondo del asunto. ${ }^{61}$

e) El primer caso en el que la Corte IDH condenó a México fue el de Castañeda Gutman, por resolución del 6 de agosto de 2008. Jorge Castañeda Gutman intentó ser candidato independiente a la presidencia de la República; solicitó al órgano electoral (IFE) su inscripción con ese carácter, el cual le fue negado. El "agraviado" se amparó y el caso llegó hasta la SCJN al atraerlo para su conocimiento; ésta resolvió que el amparo

59 García Ramírez, Sergio (coord.), La jurisprudencia de la Corte Interamericana..., cit., 2006, t. II, contiene los textos de las OC.17/02 y 18/02, esta última en las pp. 817-837; disponible en http: / / www.corteidh.or.cr/pais,cfm?id_Pais=20.

${ }^{60}$ Carmona Tinoco, Jorge Ulises, Algunos aspectos de la participación de México ante..., cit., pp. 45 y 46 .

${ }^{61}$ Carmona Tinoco, Jorge Ulises, "El caso Alfonso Martín del Campo Dodd vs. Estados Unidos Mexicanos, ante la Corte Interamericana de Derechos Humanos", Revista Latinoamericana de Derecho, Buenos Aires, UNAM, Instituto de Investigaciones Jurídicas-Rubinzal Culzoni, 2006, año III, núm. 6, pp. 73-90. 
era improcedente y que el Tribunal Electoral (TEPJF) era incompetente para conocer la impugnación de un acto que implicara el examen de la constitucionalidad de la ley en la que se basó ese acto. Como el juicio de amparo es improcedente para la defensa de los derechos políticos y los individuos no son titulares de la acción de inconstitucionalidad, los mexicanos, como personas, no contábamos con recurso alguno para defender nuestros derechos políticos.

México informó a la Corte que había efectuado en noviembre de 2007 una reforma constitucional para facultar expresamente alTEPJF a ejercer la atribución que la mencionada tesis jurisprudencial de la SCJN le había suprimido y, además, que la norma secundaria precisaría dicha facultad para que "mediante dicho recurso se garantice a los ciudadanos de forma efectiva el cuestionamiento de la constitucionalidad de la regulación legal del derecho de ser elegido”.

La Corte IDH consideró que México violaba el artículo 25 de la Convención Americana, debido a que el orden interno no contemplaba la existencia de "un recurso sencillo y efectivo para el reclamo de la constitucionalidad de los derechos políticos".

Esa Corte resolvió que la inexistencia de un recurso efectivo en tal situación había constituido una violación a la Convención Americana, y condenó a México a publicar en el Diario Oficial y en otro, por una sola vez, algunas partes de la sentencia, como una forma de reparación, y a pagar siete mil dólares por reintegro de costas y gastos.

Debe quedar claro que la Corte IDH no consideró que la cuestión planteada de las candidaturas independientes violara artículo alguno de la Convención Americana, que lo que resultaba contrario a la Convención era la ausencia de un recurso efectivo para la defensa de los derechos políticos.

La resolución en el fondo no le otorgó la razón a Jorge Castañeda ni a la CIDH. Empero, aquella sirvió para que la Corte IDH estableciera criterios jurisprudenciales de importancia excepcional:

162. Previo a ello, la Corte considera necesario señalar que, en términos generales, el derecho internacional no impone un sistema electoral determinado ni una modalidad determinada de ejercer los derechos a votar y a ser elegido. Ello se desprende de las normas que regulan los derechos políticos tanto en el ámbito 
universal como en el regional, y de las interpretaciones autorizadas realizadas por sus órganos de aplicación.

204. Finalmente, la Corte considera que ambos sistemas, uno construido sobre la base exclusivamente de partidos políticos, y otro que admite también candidaturas independientes, pueden ser compatibles con la Convención y, por lo tanto, la decisión de cuál sistema escoger está en las manos de la definición política que haga el Estado, de acuerdo con sus normas constitucionales. A la Corte no se le escapa que en la región existe una profunda crisis en relación con los partidos políticos, los poderes legislativos y con quienes dirigen los asuntos públicos, por lo que resulta imperioso un profundo y reflexivo debate sobre la participación y representación política, la transparencia y el acercamiento de las instituciones a las personas, en definitiva, sobre el fortalecimiento y la profundización de la democracia. La sociedad civil y el Estado tienen la responsabilidad, fundamental e inexcusable de llevar a cabo esta reflexión y realizar propuestas para revertir esta situación. En este sentido los Estados deben valorar de acuerdo con su desarrollo histórico y político las medidas que permitan fortalecer los derechos políticos y la democracia, y las candidaturas independientes pueden ser uno de esos mecanismos, entre muchos otros.

No obstante, la Corte fue muy clara en precisar que sí es competente si la estructura político-electoral lesiona derechos humanos reconocidos en la Convención Americana, lo cual no acontecía en el asunto en cuestión:

161.... Sin embargo, las medidas que los Estados adoptan con el fin de garantizar el ejercicio de los derechos convencionales no están excluidas de la competencia de la Corte Interamericana cuando se alega una violación de los derechos humanos previstos en la Convención. Consecuentemente, la Corte debe examinar si uno de esos aspectos vinculados a la organización y reglamentación del proceso electoral y de los derechos políticos, la exclusividad de nominación de candidatos a cargos federales por parte de los partidos políticos, implica una restricción indebida a los derechos humanos consagrados en la Convención.

174. Salvo algunos derechos que no pueden ser restringidos bajo ninguna circunstancia, como el derecho a no ser objeto de tortura o de tratos o penas crueles, inhumanos o degradantes, los derechos humanos no son absolutos. Como lo ha establecido anteriormente el Tribunal, la previsión y aplicación de requisitos 
para ejercitar los derechos políticos no constituyen, per se, una restricción indebida a los derechos políticos. Sin embargo, la facultad de los Estados de regular o restringir los derechos no es discrecional, sino que está limitada por el derecho internacional que exige el cumplimiento de determinadas exigencias que de no ser respetadas transforma la restricción en ilegítima y contraria a la Convención Americana. Conforme a lo establecido en el artículo 29. a in fine de dicho tratado ninguna norma de la Convención puede ser interpretada en sentido de limitar los derechos en mayor medida que la prevista en ella.

176. El primer paso para evaluar si una restricción a un derecho establecido en la Convención Americana es permitida a la luz de dicho tratado consiste en examinar si la medida limitativa cumple con el requisito de legalidad. Ello significa que las condiciones y circunstancias generales que autorizan una restricción al ejercicio de un derecho humano determinado deben estar claramente establecidas por ley. La norma que establece la restricción debe ser una ley en el sentido formal y material.

179. La Corte observa que el requisito por el cual corresponde a los partidos políticos solicitar el registro de los candidatos a cargos electivos a nivel federal se encuentra previsto en el artículo 175 del COFIPE, una ley en sentido formal y material ${ }^{62}$.

Eduardo Ferrer Mac-Gregor y Fernando Silva García, en un cuidadoso estudio, consideran que la resolución de la Corte IDH en el caso Castañeda es trascendente por las tesis que contiene y de las cuales destacan tres de alcance general: a) al ser la Corte IDH el intérprete final de la Convención Americana, los Estados parte deben respetar la jurisprudencia que construye; $b$ ) además del control de convencionalidad de las leyes nacionales que la Corte Interamericana realiza, también extiende dicho control en relación con la jurisprudencia constitucional nacional, y c) el control judicial de las leyes en el ámbito interamericano es un derecho humano, en cuanto en el orden jurídico interno de los Estados no debe existir ninguna zona de inmunidad "para el control de

${ }^{62}$ Corte IDH, Caso Castañeda Gutman vs. Estados Unidos Mexicanos. Excepciones preliminares, Fondo, Reparaciones y Costas, sentencia del 6 de agosto de 2008, Serie C, núm. 184, los números de los párráfos son los señalados en los textos transcritos de la sentencia. 
constitucionalidad de las leyes que impliquen violación a los derechos humanos". ${ }^{63}$

Jorge Castañeda Gutman consideró que la resolución de la Corte IDH constituía un triunfo para él, en cuanto se ordenó la publicación de aquélla y el pago de costas y gastos. No se refirió a que su pretensión, respecto a que la negación de candidaturas independientes violaba la Convención Americana, fue desestimada, tampoco a que las diversas peticiones de indemnización por daños materiales e inmateriales no prosperaron.

Así, la primera sentencia de la Corte IDH condenando a México fue, por una parte, considerada un triunfo por el peticionario y la "víctima" y, por la otra parte, el Estado mexicano también se consideró triunfador. Situación curiosa y salomónica. No obstante, más allá de las expresiones de victoria de una y otra partes, esta resolución es importante, como ya afirmé, por la trascendente jurisprudencia que configuró.

40. De agosto de 2008 - fecha de la primera sentencia condenatoria - a mayo de 2011, es decir, en el transcurso de dos años, ocho meses, la Corte IDH ha resuelto en contra del Estado mexicano 7 casos (véase la nota 53), más el Caso González y otras (Campo Algodonero) Excepción Preliminar, Fondo, Reparaciones y Costas, Sentencia del 16 de noviembre de 2009, Serie C, núm. 205.

No deja de sorprender que en un lapso tan corto - menos de tres años - el Estado mexicano haya sido condenado internacionalmente cuando con anterioridad no había sucedido, y México guardaba prestigio como un país respetuoso de los tratados internacionales ratificados y del derecho internacional de los derechos humanos. Tal vez este dato sea un síntoma más del fuerte deterioro que como país ha sufrido en diversos aspectos, cuando menos en los últimos dieciocho años.

41. Resulta preocupante que la Corte IDH tenga la percepción de que el Estado mexicano no cumple con sus sentencias ni con su juris-

63 Ferrer Mac-Gregor, Eduardo y Silva García, Fernando, El caso Castañeda ante la Corte Interamericana de Derechos Humanos. La primera sentencia internacional condenatoria en contra del Estado mexicano, México, Porrúa-UNAM, Instituto de Investigaciones Jurídicas, 2009, pp. 69 y 70. Sobre el caso Castañeda Gutman, véase Carmona Tinoco, Jorge Ulises, El caso Jorge Castañeda Gutman vs. Estados Unidos Mexicanos ante la Corte Interamericana de Derechos Humanos, disponible en http://biblio.juridicas.unam.mx/estrev/derint/cont/9/pim/pim29.htm. 
prudencia; así se lo ha hecho saber en el Caso Cabrera García y Montiel Flores vs. México (citado en la nota 53) de noviembre de 2010; incluso se podría estimar que la Corte IDH "regañó” al Estado mexicano por dicho incumplimiento, aunque en el lenguaje diplomático y jurídico que una Corte de esa naturaleza y jerarquía debe utilizar:

233. De tal manera, como se indicó en los Casos Radilla Pacheco, Fernández Ortega y Rosendo Cantú, es necesario que las interpretaciones constitucionales y legislativas referidas a los criterios de competencia material y personal de la jurisdicción militar en México, se adecuen a los principios establecidos en la jurisprudencia de este Tribunal que han sido reiterados en el presente caso y que aplican para toda violación de derechos humanos que se alegue hayan cometido miembros de las fuerzas armadas. Ello implica que, independientemente de las reformas legales que el Estado deba adoptar, en el presente caso corresponde a las autoridades judiciales, con base en el control de convencionalidad, disponer inmediatamente y de oficio el conocimiento de los hechos por el juez natural, es decir el fuero penal ordinario.

¿Será que la Corte IDH comienza a impacientarse con la actitud esquiva y poco colaboradora de México?

En el caso Radilla Pacheco vs. Estados Unidos Mexicanos, la Corte IDH dictó sentencia condenando al gobierno mexicano el 23 de noviembre de 2009. Sobre el mismo caso volvió a resolver en relación con la supervisión del cumplimiento de esa sentencia el 19 de mayo de 2011, y constató que únicamente se había cumplido con un punto resolutivo, la publicación de extractos de dicha sentencia en el Diario Oficial de la Federación.

Por el contrario, aún se encontraban pendientes de cumplimiento nueve puntos resolutivos, entre los que destaca que hay que "adoptar, en un plazo razonable, las reformas legislativas pertinentes para compatibilizar el artículo 57 del Código de Justicia Militar con los estándares internacionales en la materia y con la Convención Americana sobre Derechos Humanos". ${ }^{64}$

${ }^{64}$ En relación con el caso Radilla, véase la interesante obra de Ferrer Mac-Gregor, Eduardo y Silva García, Fernando, Jurisdicción militar y derechos humanos. El caso Radilla ante la Corte 
42. En las sentencias de la Corte IDH, con frecuencia, se resuelve el pago de indemnizaciones y reparaciones económicas.

En junio de 2002 se reformó la Constitución mexicana; su título V fue adicionado. Con anterioridad se denominaba "De las responsabilidades de los Servidores Públicos” para agregarle "y patrimonial del Estado”, y al artículo 113 constitucional se le añadió un segundo párrafo:

La responsabilidad del Estado por los daños que, con motivo de su actividad administrativa irregular cause en los bienes o derechos de los particulares, será objetiva y directa. Los particulares tendrán derecho a una indemnización conforme a las bases, límites y procedimientos que establezcan las leyes.

El artículo transitorio fijó plazo para la expedición de las leyes reglamentarias de carácter federal y local — entidades federativas y Distrito Federal- .

La Ley Federal de la Responsabilidad Patrimonial del Estado entró en vigor el 1o. de enero de 2005; en su artículo 2o. párrafo 2, y en el capítulo III se regulan el principio y el procedimiento para el cumplimiento de las indemnizaciones - cuyas modalidades y precisiones se encuentran en el capítulo II- establecidas por diversos órganos, entre los que se encuentra la Corte IDH y sus resoluciones. ${ }^{65}$

Para tener una idea del gran avance de esa reforma constitucional y de su ley reglamentaria, recuerdo que con anterioridad a 1994 la responsabilidad patrimonial del Estado era subsidiaria; había que seguir un proceso civil ordinario contra los servidores públicos que habían causado el daño y perjuicio, y únicamente si resultaban insolventes se abría la posibilidad de comenzar un nuevo juicio civil contra el gobierno federal o local, al que esos servidores públicos pertenecían. A partir de 1994 dicha responsabilidad del Estado se tornó solidaria. Con la reforma al artículo 113 constitucional de 2001 y la correspondiente ley, esa responsabilidad se convirtió en objetiva y directa.

Interamericana de Derechos Humanos, México, Porrúa y UNAM-Instituto de Investigaciones Jurídicas, 2011, $634 \mathrm{pp}$.

65 Castro Estrada, Álvaro, Nueva garantía constitucional. La responsabilidad patrimonial del Estado, México, Porrúa, 2005, 434 pp. 
43. Nuestro Poder Judicial de la Federación comienza a utilizar la jurisprudencia de la Corte IDH, así como sus criterios en opiniones consultivas; por ejemplo: en el amparo directo 30/2008; en los amparos directos en revisión 2019/2006, 757/2007, 871/2007, 1624/2008, 75/2009; en los amparos en revisión 287/2007, 514/2007, 715/2007, $976 / 2007$ y otros. ${ }^{66}$

Un Tribunal Colegiado de Circuito estableció la tesis siguiente:

JURISPRUDENCIA INTERNACIONAL. SU UTILIDAD ORIENTADORA EN MATERIA DE DERECHOS humanos. Una vez incorporados a la Ley Suprema de toda la Unión los tratados internacionales suscritos por México, en materia de derechos humanos, y dado el reconocimiento de la competencia contenciosa de la Corte Interamericana de Derechos Humanos, es posible invocar la jurisprudencia de dicho tribunal internacional como criterio orientador cuando se trate de la interpretación y cumplimiento de las disposiciones protectoras de derechos humanos. ${ }^{67}$

Fue una tesis tímida pero valiosa, que mostró una tendencia clara e irreversible, y que pronto se fortalecería.

Asimismo, el TEPJF, en sus sentencias, se ha apoyado en la jurisprudencia de la Corte IDH. ${ }^{68}$

44. Los tribunales federales comienzan a realizar el control difuso de convencionalidad; será una corriente imparable:

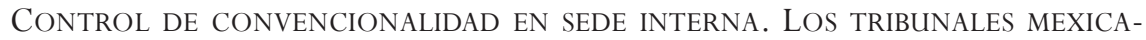
NOS ESTÁN OBLIGADOS A EJERCERLO. Tratándose de los derechos humanos, los tribunales del Estado mexicano como no deben limitarse a aplicar sólo las leyes locales, sino también la Constitución, los tratados o convenciones internacionales conforme a la jurisprudencia emitida por cualesquiera de los tribunales internacionales que realicen la interpretación de los tratados, pactos, convenciones o

${ }^{66}$ Castilla Juárez, Karlos, "Los primeros pasos para la construcción del diálogo jurisprudencial en materia de derechos humanos: tribunales nacionales-tribunales internacionales", Reforma Judicial. Revista Mexicana de Justicia, México, UNAM, Instituto de Investigaciones Jurídicas, 2009, núm. 14, pp. 168-186.

67 Semanario Judicial de la Federación y su Gaceta, 2008, t. XXVIII, p. 1052. Es la tesis 1.7o.C.51K, tesis aislada del Séptimo Tribunal Colegiado en Materia Civil del Primer Circuito. Amparo directo $623 / 2008$.

68 Carmona Tinoco, Jorge Ulises, La recepción de la jurisprudencia de la Corte Interamericana de Derechos Humanos..., cit., pp. 267, 286-289. 
acuerdos celebrados por México; lo cual obliga a ejercer el control de convencionalidad entre las normas jurídicas internas y las supranacionales, porque éste implica acatar y aplicar en su ámbito competencial, incluyendo las legislativas, medidas de cualquier orden para asegurar el respeto de los derechos y garantías, a través de políticas y leyes que los garanticen. ${ }^{69}$

Control de Convencionalidad. Debe ser ejercido por los JUECES Del EsTADO MEXICANO EN LOS ASUNTOS SOMETIDOS A SU CONSIDERACIÓN, A FIN DE VERIFICAR QUE LA LEGISLACIÓN INTERNA NO CONTRAVENGA EL OBJETO Y FINALidad de la Convención Americana sobre Derechos Humanos. La Corte Interamericana de Derechos Humanos ha emitido criterios en el sentido de que, cuando un Estado, como en este caso México, ha ratificado un tratado internacional, como lo es la Convención Americana sobre Derechos Humanos, sus Jueces, como parte del aparato estatal, deben velar porque las disposiciones ahí contenidas no se vean mermadas o limitadas por disposiciones internas que contraríen su objeto y fin, por lo que se debe ejercer un "control de convencionalidad" entre las normas de derecho interno y la propia convención, tomando en cuenta para ello no sólo el tratado, sino también la interpretación que de él se ha realizado. Lo anterior adquiere relevancia para aquellos órganos que tienen a su cargo funciones jurisdiccionales, pues deben tratar de suprimir, en todo momento, prácticas que tiendan a denegar o delimitar el derecho de acceso a la justicia. ${ }^{70}$

45. Ya apunté con argumentos por qué la jurisprudencia de la Corte IDH es obligatoria para los Estados partes que han reconocido su competencia contenciosa. En América Latina son varios países, cuyas cortes, tribunales o salas constitucionales lo admiten expresamente en sus resoluciones. Al respecto son paradigmáticas las de Argentina, Colombia y Costa Rica. ${ }^{71}$

${ }^{69}$ Semanario Judicial de la Federación y su Gaceta, 2010, t. XXXI, p. 1932. Es la tesis XI, $1^{\circ}$, A, T, 47K, del Primer Tribunal Colegiado en Materias Administrativa y de Trabajo del Décimo Primer Circuito. Amparo directo 1060/2008.

70 Semanario Judicial de la Federación y su Gaceta, 2010, t. XXXI, p. 2927. Es la tesis I, $4^{\circ}$. A. 91K, del Cuarto Tribunal Colegiado en Materia Administrativa del Primer Circuito. Amparo directo 505/2009.

71 Ayala Corao, Carlos M., "Recepción de la jurisprudencia internacional sobre derechos humanos por la jurisprudencia constitucional”, en Eduardo Ferrer Mac-Gregor (ed.), Derecho procesal constitucional, México, Porrúa, 2006, t. II, pp. 1519-1525. 
46. A nuestra SCJN le está costando trabajo aceptar las sentencias y jurisprudencia de la Corte IDH.

Un ejemplo lo encuentro en la actitud aparentemente dubitativa del distinguido y liberal ministro Juan Silva Meza, actual presidente de nuestra Suprema Corte (2011- ), quien en una importante obra señala:

... la circunstancia de que las sentencias firmes y la jurisprudencia de las altas cortes nacionales puedan examinarse ante la $\mathrm{CIDH}$, ha puesto de manifiesto que los tribunales regionales cuentan con una autoridad interpretativa frente a los tribunales constitucionales, derivada de la propia lógica del control jurisdiccional externo del Estado en ese ámbito.

Páginas más adelante indica que la relación de los tratados internacionales sobre derechos humanos con la Constitución nacional es de complementariedad, más que de jerarquía, y tienen una presunción muy fuerte, que su contenido suplementa, no contraviene la ley fundamental. En México, los tratados, desde una perspectiva formal y nacional, se encuentran jerárquicamente abajo de la Constitución, pero desde una perspectiva material conforman un orden jurídico superior, y la Constitución es "potencialmente integrable por los contenidos adicionales de la normativa de producción externa". ${ }^{72}$

47. En tiempos recientes se habla de diálogo jurisprudencial. Por él se entiende que, en el caso de nuestro país, los jueces nacionales conozcan y apliquen, en un control convencional, los criterios jurisprudenciales de los tribunales internacionales, en forma especial de la Corte IDH, pero, a su vez, que ésta valore lo que los tribunales nacionales (en forma relevante la SCJN y el TEPJF) han resuelto en relación con la protección de un determinado derecho humano, sin que lo anterior implique la aceptación de cualquier interpretación. ${ }^{73}$

Yo diría que, más que diálogo, es el conocimiento indispensable que los jueces nacionales deben tener de la jurisprudencia internacional,

72 Silva Meza, Juan N. y Silva García, Fernando, op. cit., pp. 334 y 345.

73 Castilla Juárez, Karlos, op. cit., pp. 165-167; Ferrer Mac-Gregor, Eduardo, "La Corte Interamericana de Derechos Humanos como intérprete constitucional (dimensión transnacional del derecho procesal constitucional”, en Eduardo Ferrer Mac-Gregor, (ed.), Derecho procesal constitucional, cit., pp. 1583-1585. 
en especial de aquella de la Corte IDH, que nos obliga. Los jueces, en consecuencia, deben realizar un control de convencionalidad a menos que exista en ellos desprecio por la defensa de los derechos humanos y no les interese la posibilidad de sentencias condenatorias al Estado mexicano — debido a sus resoluciones - por parte de la Corte IDH.

A su vez, útil es que la Corte IDH conozca la jurisprudencia de la SCJN, y sus argumentos sobre las peculiaridades y el contexto nacional que puedan ser aceptados por no violar la Convención Americana o, de plano, rechazados si la violan.

Ese conocimiento mutuo, armonización o "diálogo" parte de una premisa: por el principio pro homine se debe aplicar la norma que mejor proteja al individuo, ya sea que pertenezca al orden jurídico interno o al externo; este último en realidad, se ha convertido en interno de acuerdo con el artículo 133 constitucional.

\section{LOS COMITÉS DE NACIONES UNIDAS PARA LA PROTECCIÓN DE LOS DERECHOS HUMANOS Y LA CORTE PENAL INTERNACIONAL}

48. Naciones Unidas cuenta con varios órganos especializados en la protección de los derechos humanos, los que, inclusive, están facultados para recibir quejas individuales y prescribir recomendaciones a los Estados. México ha reconocido a varios de esos órganos.

El Protocolo Facultativo del Pacto sobre Derechos Civiles y Políticos de 1966 —ratificado por México en 2002 — creó el Comité de Derechos Humanos, integrado por 18 expertos electos a título personal, y que tiene atribuciones parajudiciales parecidas a las de la $\mathrm{CIDH}$.

Del Consejo Económico y Social de la ONU dependen el Consejo de Derechos Humanos y su órgano técnico de Promoción y Protección de los Derechos Humanos, que cuenta con 26 expertos de las distintas regiones. $^{74}$

Además, se pueden mencionar el Comité para la eliminación de la Discriminación Racial, el Comité para la Eliminación de la Discrimina-

74 Fix-Zamudio, Héctor, La creciente internacionalización de las Constituciones iberoamericanas..., cit., pp. 84, 151 y 165 . 
ción en contra de la Mujer y el Comité contra la Tortura y otros Tratos o Penas Crueles, Inhumanos y Degradantes. ${ }^{75}$ Estos tres también reconocidos por nuestro país.

Hasta ahora, la presentación de peticiones individuales ante los Comités de Naciones Unidas es escasa por parte de mexicanos. La razón tal vez consista en que es más conocida la Comisión Interamericana, debido a su antigüedad, a que ha tramitado casos que han tenido amplia difusión en los medios de comunicación, y a que se le siente más cercana en razón de que, en diversos periodos, la Comisión Interamericana ha estado y está integrada por algún distinguido mexicano.

49. En octubre de 2005 se reformó nuestra Constitución para adicionar al artículo 21 un párráfo, que es el octavo: "El Ejecutivo Federal podrá, con la aprobación del Senado en cada caso, reconocer la jurisdicción de la Corte Penal Internacional" (CPI), ubicada en La Haya, Holanda; Corte cuyo Estatuto, tres años antes, había alcanzado el número de ratificaciones para lograr su existencia.

El preámbulo de la Convención de Roma, mediante la cual los Estados signatarios crearon la CPI, afirma que esa Corte tendrá carácter permanente, "independiente y vinculada con el sistema de las Naciones Unidas que tenga competencia sobre los crímenes más graves de trascendencia para la comunidad internacional en su conjunto y que sea complementaria de las jurisdicciones penales nacionales", aspectos medulares que recoge su Estatuto en el artículo 1 o.

Las características de ese sistema penal internacional están definidas en los mencionados enunciados, y son ocho. ${ }^{76}$

La CPI juzga exclusivamente a individuos y no remplaza al derecho nacional; sólo actúa cuando existen procesos fraudulentos, demoras o ausencia de voluntad del Estado para investigar o juzgar; cuando el proceso no garantiza o garantizó independencia o imparcialidad; cuando no existe la intención de hacer comparecer a la persona ante la justicia, o el Estado no tiene la capacidad para investigar o enjuiciar el caso.

75 Véase Carmona Tinoco, Jorge Ulises, El significado de la aceptación de la competencia de los comités de Naciones Unidas, facultados para decidir peticiones individuales en materia de derechos humanos y su previsible impacto en la impartición de justicia en México, disponible en: http: / /www. juridicas.unam. $\mathrm{mx} / \mathrm{publica/rev/refjud/cont/1/cle/cle14.htm.}$

76 García Ramírez, Sergio, La Corte Penal Internacional, México, INACIPE, 2004, pp. 35-38. 
La CPI tiene características diversas a la protección de los derechos humanos a nivel internacional. La más importante es que no conoce de responsabilidades del Estado sino de individuos.

El inicio de la investigación por parte del fiscal de la CPI puede responder a la solicitud de un Estado, del Consejo de Seguridad de Naciones Unidas o motu proprio.

La competencia de la CPI abarca exclusivamente a delitos extraordinariamente graves: genocidio, crimen de lesa humanidad, crímenes de guerra, delitos contra la administración de justicia cometidos con motivo del enjuiciamiento penal internacional y crimen de agresión. El Estatuto de la CPI tipifica cada uno de ellos, salvo el de agresión, lo que requerirá una reforma a ese ordenamiento. ${ }^{77}$

El artículo 42.1 del Estatuto de la CPI creó la Fiscalía, la cual:

... actuará en forma independiente como órgano separado de la Corte. Estará encargada de recibir remisiones e información corroborada sobre crímenes de la competencia de la Corte para examinarlas y realizar investigaciones o ejercitar la acción penal ante la Corte. Los miembros de la Fiscalía no solicitarán ni cumplirán instrucciones de fuentes ajenas a la Corte”, aunque el Consejo de Seguridad puede acordar la suspensión de una investigación o de un juicio.

La forma en que México acepta la jurisdicción de la CPI es peculiar, debido a que dicha aceptación debe ser de carácter general, porque hacerlo de manera casuística y a criterio del presidente de la República puede prestarse a que intervengan consideraciones políticas, de oportunidad e incluso de opinión pública en el sentido que sea, hasta propiciar debates de los cuales los casos jurídicos deben estar lejanos. 